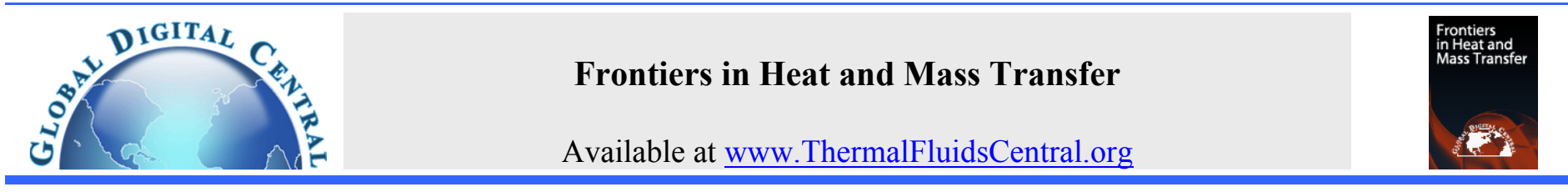

\title{
INFLUENCES OF THE PUNCHED DELTA WINGLET VORTEX GENERATORS IN A CIRCULAR TUBE HEAT EXCHANGER ON THERMO-HYDRAULIC PERFORMANCE
}

\author{
Withada Jedsadaratanachai ${ }^{\mathrm{a}}$ and Amnart Boonloi ${ }^{\mathrm{b}, *}$ \\ ${ }^{a}$ Department of Mechanical Engineering, Faculty of Engineering, King Mongkut's Institute of Technology Ladkrabang, Bangkok 10520, Thailand \\ ${ }^{b}$ Department of Mechanical Engineering Technology, College of Industrial Technology, King Mongkut's University of Technology North Bangkok, \\ Bangkok 10800, Thailand
}

\begin{abstract}
Numerical investigations on flow topology, heat transfer behavior and thermal performance evaluation in a circular tube heat exchanger with the punched delta winglet vortex generators $(P D W V G)$ inserted in the middle of the test section are presented. The effects of the flow attack angles that converging to the center of the tube; $\alpha=0^{\circ}, 5^{\circ}, 10^{\circ}, 15^{\circ}, 20^{\circ}, 25^{\circ}$, and flow directions; winglet tips pointing downstream and upstream, are investigated for the Reynolds numbers; $R e=100-2000$. The finite volume method and SIMPLE algorithm are used for the current study. The results are presented in terms of flow configuration, heat transfer behavior and thermal performance assessments and also compared with the smooth tube with no $P D W V G$. As numerical results, the use of $P D W V G$ inserted in the tube can help to improve heat transfer rate and thermal performance in the heat exchanger by creating the vortex flows through the test section. The rise of the flow attack angle and Reynolds number leads to increase in heat transfer, friction loss and thermal performance. The optimum $T E F$ is around 2.33 at $R e=2000, \alpha=25^{\circ}$ for winglet tip pointing downstream.
\end{abstract}

Keywords: Compact heat exchanger, Delta winglet, Laminar flow, Thermal enhancement factor.

\section{INTRODUCTION}

Many researches on both numerical and experimental focus the improvement on thermal performance and heat transfer rate in the heat exchanger. The improved method is done by use the vortex generators or turbulators insert in the tube or channel heat exchanger. The vortex generators can create the vortex flow or swirling flow in the heat exchanger that helps to enhance the heat transfer rate and thermal performance, but also increase the pressure. The large flow blockage ratio of the vortex generators may increase very large pressure loss in the heating system. The appropriate geometry of the vortex generators will lead to the optimum enhancement on both heat transfer rate and friction loss. The forming method and installation of the vortex generators are another important factors that must investigate. The differences of the forming and installing methods may lead to the variations of the heat and flow behaviors in the heat exchanger.

The numerical and experimental investigations, which focus on heat transfer augmentation with using various types of winglets, had been presented. Khoshvaght-Alianadi et al. (2015) presented the experimental investigations on heat transfer and pressure drop in a tube heat exchanger with delta winglets vortex generators with different arrangements. They concluded that the delta winglet vortex generators can help augment heat transfer rate, but also increase in the pressure loss. They also pointed out that the optimum value between the enhancement of the heat transfer rate and friction loss in term of performance evaluation criterion or PEC is around 1.41 at $\mathrm{Re}=8715$. Gholami et al. (2014) investigated heat transfer and pressure loss in a fin-and-tube heat exchanger with wavy rectangular winglet vortex generators by numerical method. They found that the winglet vortex generators can enhance the heat transfer rate with a moderate pressure loss penalty, especially, the wavy-up rectangular winglet. He et al. (2013) carried out to investigate the heat transfer, pressure loss and thermal performance improvement in a fin-and-tube heat exchanger with rectangular winglet vortex generators. They studied the effects of the flow attack angle, row-number of the winglet and placement of the winglet on thermo-hydraulic performance. They found that the longitudinal vortices and impinging flow are the main reasons for heat transfer augmentation in the heat exchanger. Caliskan (2014) studied the new type vortex generators; punched triangular vortex generators and punched rectangular vortex generators in a rectangular channel heat exchanger. Caliskan (2014) claimed that the punched triangular vortex generators give the best thermal performance in the heating system. Caliskan (2014) also found that the enhancement of the heat transfer is around $23-55 \%$ when compared with smooth channel. Wang et al. (2015) numerical studied the flow resistance and heat transfer in a channel heat exchanger with delta winglet vortex generators. They reported that the maximum j-factor and f-factor are around $24.96 \%$ and $17.61 \%$, respectively. Li et al. (2015) presented the heat transfer augmentation in a fin-and-tube heat exchanger with longitudinal vortex generators; rectangular winglet and delta winglet, by numerical simulation. They summarized that the rectangular winglet provides higher heat transfer rate than the delta winglet. They also showed that the flow attack angles of $25^{\circ}$ and $45^{\circ}$ perform the best thermal performance for rectangular winglet and delta winglet, respectively. Du et al. (2014) numerical investigated the influences of the punched longitudinal vortex generators in a fin-and-tube heat exchanger on heat transfer and pressure loss. They stated that the optimum thermal performance in term of the performance evaluation criteria is found at the flow attack angle of $25^{\circ}$ for the delta winglet pairs. Lofti et al. (2014) presented the three dimensional numerical investigations on

* Corresponding author. Email: amnartb@kmutnb.ac.th 
flow configuration and heat transfer characteristic in a fin-and-tube heat exchanger with various types of vortex generators. The rectangular trapezoidal winglet $(R T W)$, angle rectangular winglet $(A R W)$, curve angle rectangular winglet $(C A R W)$, wheeler wishbone $(W W)$ are types of the vortex generators that presented by Lofti et al. (2014). They reported that the $C A R W$ gives the highest thermal performance for the small attack angle, while the $R T W$ performs the best thermal performance at a large attack angle. Du et al. (2013) studied the thermal performance assessments in a fin-and-tube heat exchanger with longitudinal vortex generators; punched delta winglet pairs. They showed that the delta winglet vortex generators provide higher heat transfer rate and friction loss around $21-60 \%$ and $13-83 \%$, respectively. They also reported that the average performance evaluation criterion is around 1.31. Gong et al. (2015) investigated the punched curve rectangular vortex generators in a fin-and-tube heat exchanger on heat transfer behavior and flow topology. They informed that the vortex generators can help to enhance the local Nussel number on the fin surfaces, which contact to the wake regimes. Ebrahimi et al. (2015) informed the effects of the longitudinal vortex generators in a rectangular microchannel on flow structure and heat transfer configuration by numerical investigation. They found that the enhancement of the Nusselt number and friction loss are around $2-$ $25 \%$ and $4-30 \%$, respectively. Deshmukh and Vedula (2014) reported the influences of the projected length ratio, height to tube inner diameter ratio and flow attack angle of curved delta wing vortex generators inserted in a circular tube heat exchanger on thermal performance. They claimed that the Nusselt number for the tube heat exchanger with vortex generators is around $1.3-5.0$ times higher than the smooth tube with no vortex generators. He et al. (2012) studied the heat transfer augmentation in a fin-and tube heat exchanger with punched winglet vortex generators. They found that the heat transfer rate and pressure loss increase with the rise of the flow attack angle. They also summarized that the improvements of the heat transfer rate and friction loss are around $33.8-70.6 \%$ and $43.4-97.2 \%$ for the flow attack angle of $30^{\circ}$, respectively. Min et al. (2012) numerical simulated on turbulent flow and heat transfer behaviors in a channel heat exchanger with novel longitudinal vortex generators. They presented that the combined longitudinal vortex generators can generate vortices with larger regimes when compared with normal longitudinal vortex generators. Wu et al. (2012) experimental studied the punched longitudinal vortex generators; delta winglet pairs, in a fin-and-tube heat exchanger on heat transfer characteristic and flow configuration. They reported that the common-flow-up and common-flow-down of the delta winglet vortex generators give higher heat transfer rate around $16.5 \%$ and $28.2 \%$, respectively, when compared with plain fin. $\mathrm{Wu}$ and Tao (2012) presented the effects of the longitudinal vortex generators; punched delta winglet, in a rectangular channel heat exchanger on thermal performance. They reported the effect of different punched angles; $15^{\circ}, 30^{\circ}, 45^{\circ}$ and $60^{\circ}$ by numerical and experimental investigations. They informed that the angle of $60^{\circ}$ performs higher heat transfer rate and pressure loss than $45^{\circ}$.

As the literature reviews, it can be concluded as follows:

- The use of the winglets in the heat exchangers can help to improve heat transfer rate and thermal performance by generating the vortex flow, longitudinal vortex flow, impinging flow in the test section.

- The presences of the winglet not only increase in heat transfer rate, but also give higher pressure loss, especially in case of the high flow blockage area.

- The rectangular winglet performs higher heat transfer rate and friction factor than the delta winglet.

- The delta winglet can help to reduce the pressure loss in the heating system.

- The numerical investigation can save time and cost to study the thermal performance in the heat exchanger and also help to report the flow and heat transfer structure, which are ways to improve thermal performance.
Therefore, the numerical investigations on heat transfer and flow resistance in a tube heat exchanger with the punched delta winglet vortex generators are presented in the current study. The objective of this work is to enhance the heat transfer rate and thermal performance in the tube heat exchanger with a moderate pressure loss penalty. The comfortable for forming and installing of the vortex generators is another aim in this investigation. The influences of the flow attack angles; $0^{\circ}, 5^{\circ}, 10^{\circ}, 15^{\circ}, 20^{\circ}$ and $25^{\circ}$, and flow directions; winglet tip pointing downstream and upstream, are investigated for the Reynolds numbers, $R e=100-2000$.

\section{BOUNDARY CONDITION AND ASSUMPTION}

The boundary conditions for the current computational domain are presented as table 1:

Table 1 the boundary condition for the current computational domain.

\begin{tabular}{|l|l|}
\hline Zone & Boundary condition \\
\hline Inlet, outlet & Periodic condition \\
\hline Tube wall & Constant temperature at 310 K \\
\hline Tested fluid & $\begin{array}{l}\text { - Air, constant mass flow rate at } 300 \mathrm{~K} \\
\text { - Constant properties at the average } \\
\text { temperature }\end{array}$ \\
\hline Perpendicular plate & Adiabatic wall condition \\
\hline Punched delta winglet & Adiabatic wall condition \\
\hline
\end{tabular}

The current investigations on both flow configuration and heat transfer behavior are developed under following assumptions:

- $\quad$ Steady three-dimensional fluid flow and heat transfer.

- The flow is laminar and incompressible.

- Constant fluid properties.

- $\quad$ Body forces and viscous dissipation are ignored.

- Negligible radiation heat transfer.

\section{MATHEMATICAL FOUNDATION}

Based on the above assumptions, the flow in circular tube is governed by the continuity, the Navier-Stokes and the energy equations. In the Cartesian tensor system these equations can be written as follows:

Continuity equation:

$\frac{\partial}{\partial x_{i}}\left(\rho u_{i}\right)=0$

Momentum equation:

$\frac{\partial\left(\rho u_{i} u_{j}\right)}{\partial x_{j}}=-\frac{\partial p}{\partial x_{i}}+\frac{\partial}{\partial x_{j}}\left[\mu\left(\frac{\partial u_{i}}{\partial x_{j}}+\frac{\partial u_{j}}{\partial x_{i}}\right)\right]$

Energy equation:

$\frac{\partial\left(\rho u_{i} T\right)}{\partial x_{i}}=\frac{\partial}{\partial x_{j}}\left(\Gamma \frac{\partial T}{\partial x_{j}}\right)$

where, $\Gamma$ is the thermal diffusivity and is given by

$\Gamma=\frac{\mu}{\operatorname{Pr}}$

Apart from the energy equation discretize by the QUICK scheme, the governing equations are discretized by the second order upwind (SOU) scheme, decoupling with the SIMPLE algorithm, and solved by 
using a finite volume approach (Patankar, 1980). The solutions were considered to be converged when the normalized residual values were less than $10^{-5}$ for all variables, but less than $10^{-9}$ only for the energy equation.

Four parameters of interest in the present work are the Reynolds number, friction factor, Nusselt number and thermal enhancement factor. The Reynolds number is defined as:

$$
\operatorname{Re}=\rho \overline{\mathrm{u}} / \mu
$$

The friction factor, $f$ is computed by pressure drop, $\Delta p$, across the length of the periodic tube, $L$, as

$$
\mathrm{f}=\frac{(\Delta \mathrm{p} / \mathrm{L}) \mathrm{D}}{\frac{1}{2} \rho \overline{\mathrm{u}}^{2}}
$$

The heat transfer is measured by the local Nusselt number which can be written as

$$
\mathrm{Nu}_{\mathrm{x}}=\frac{\mathrm{h}_{\mathrm{x}} \mathrm{D}}{\mathrm{k}}
$$

The average Nusselt number can be obtained by

$$
\mathrm{Nu}=\frac{1}{\mathrm{~L}} \int \mathrm{Nu}_{\mathrm{x}} \partial \mathrm{x}
$$

The thermal enhancement factor $(T E F)$ is defined as the ratio of the heat transfer coefficient of an augmented surface, $h$ to that of a smooth surface, $\mathrm{h}_{0}$, at an equal pumping power and given by

$$
\mathrm{TEF}=\left.\frac{\mathrm{h}}{\mathrm{h}_{0}}\right|_{\mathrm{pp}}=\left.\frac{\mathrm{Nu}}{\mathrm{Nu}_{0}}\right|_{\mathrm{pp}}=\left(\mathrm{Nu} / \mathrm{Nu}_{0}\right) /\left(\mathrm{f} / \mathrm{f}_{0}\right)^{1 / 3}
$$

where $N u_{0}$ and $f_{0}$ stand for Nusselt number and friction factor for the smooth tube, respectively.

\section{COMPUTATIONAL MODEL}

The computational domain of the $P D W V G$ in the circular tube heat exchanger is shown in Fig. 1, while the differences of the flow attack angle for the turbulators is presented in Fig. 2. The circular tube diameter, $D$, is set at $0.05 \mathrm{~m}$. The $P D W V G$ s are punched out from the perpendicular plates, while the plate width equals to the tube diameter on both vertical and horizontal plates. The length and height of the winglet are set to $0.55 \mathrm{D}$ and $0.2 \mathrm{D}$, respectively. The flow attack angles; $0^{\circ}, 5^{\circ}, 10^{\circ}, 15^{\circ}, 20^{\circ}, 25^{\circ}$, flow directions; winglet tip pointing downstream and upstream, are investigated numerically for the Reynolds numbers; $R e=100-2000$.

The numbers of grid are tested by creating the four sets of cells; $80000,120000,200000,300000$ for the current computational domain. It is found that the increase of the grid from 120000 to 200000 has no effect on both heat transfer and friction factor. The variations of the Nusselt number and friction loss are around $\pm 0.03 \%$ and $\pm 0.1 \%$, respectively. Therefore, the grid cells around 120000 are used for the current computational domain when considering on both time and accuracy result.

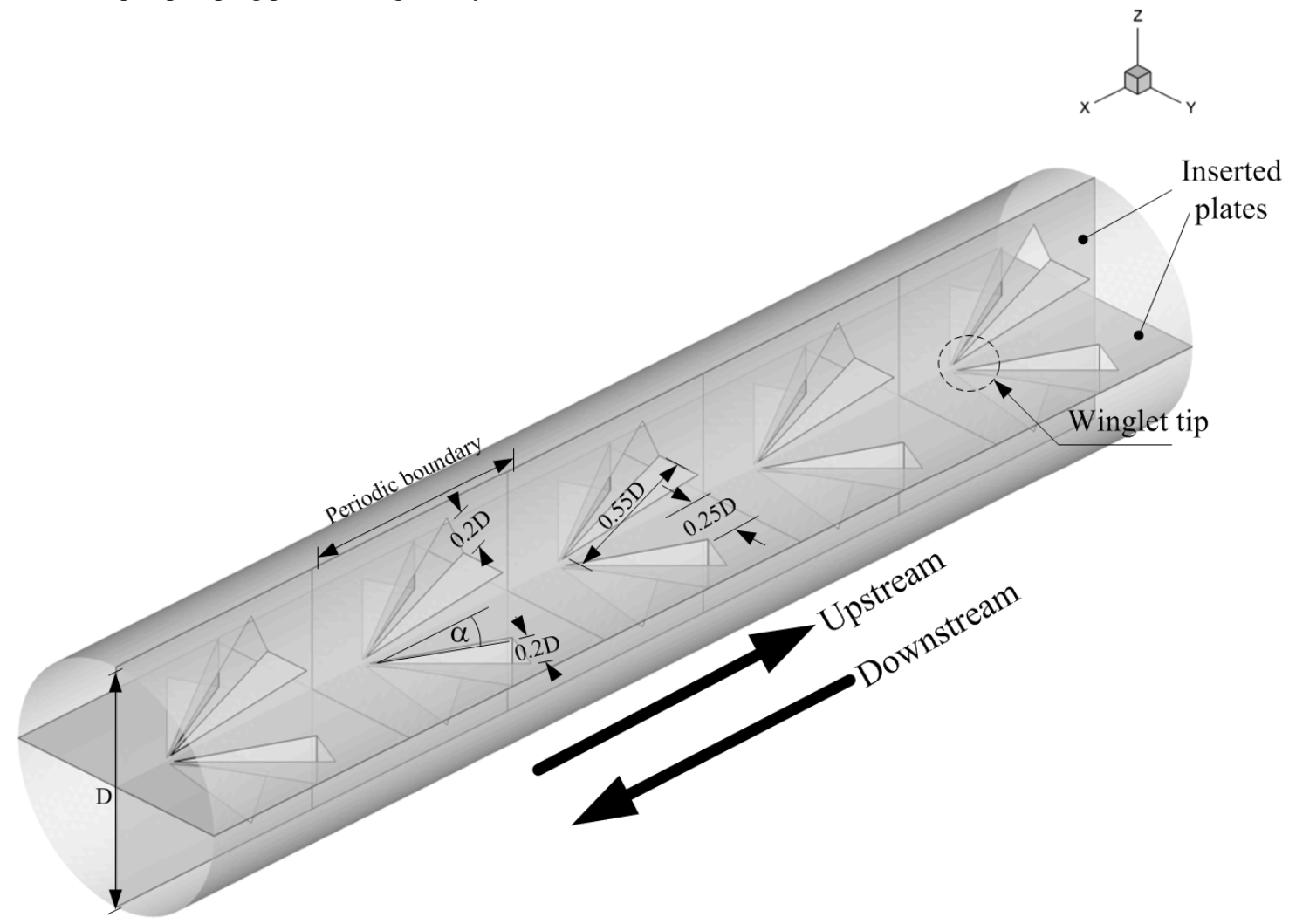

Fig. 1 Computational domain of the tube heat exchanger inserted with the $P D W V G$ in the middle of the test tube. 

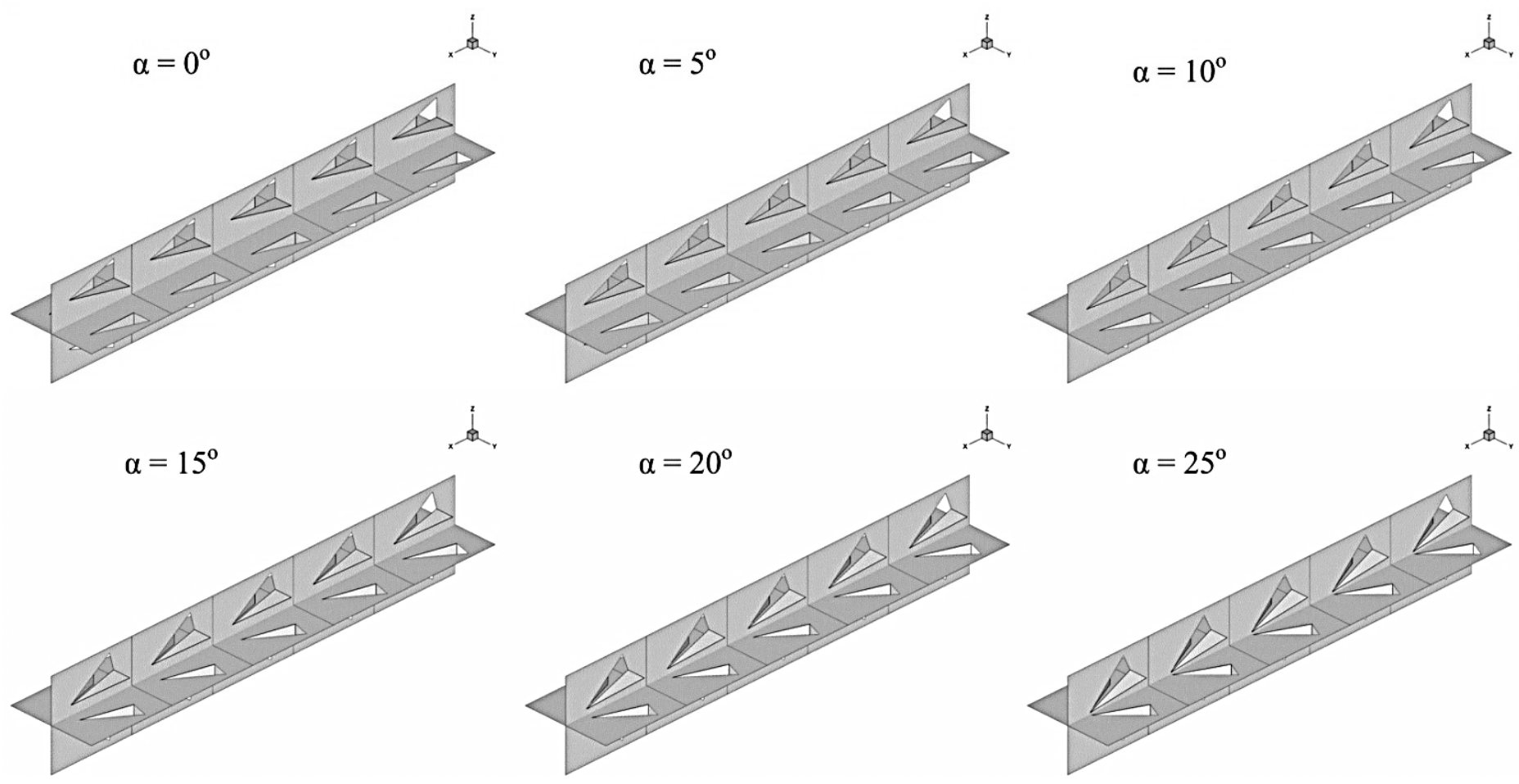

Fig. 2 The punched delta winglet vortex generators with various the flow attack angles.

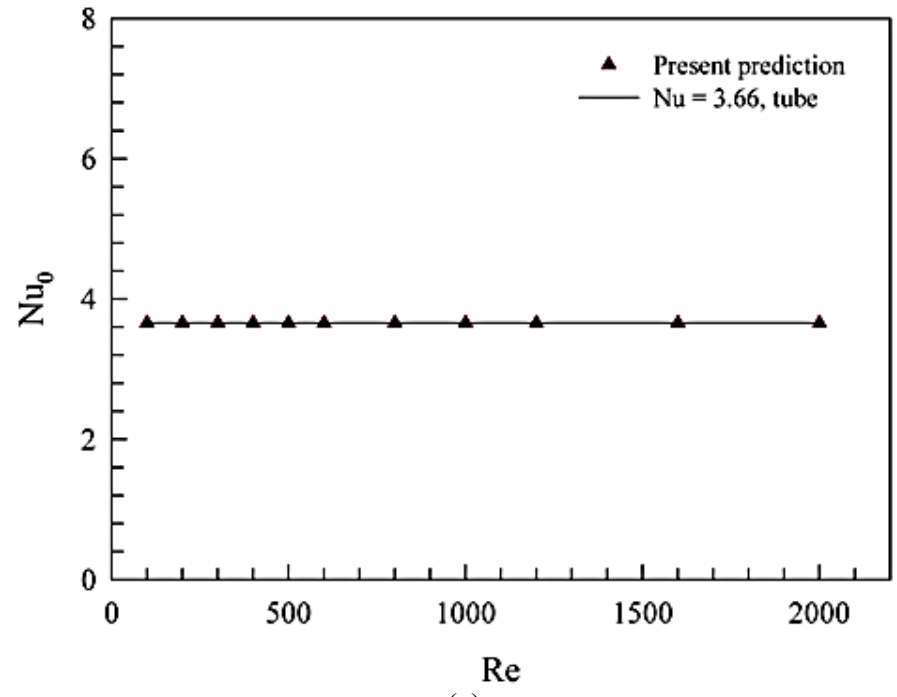

(a)

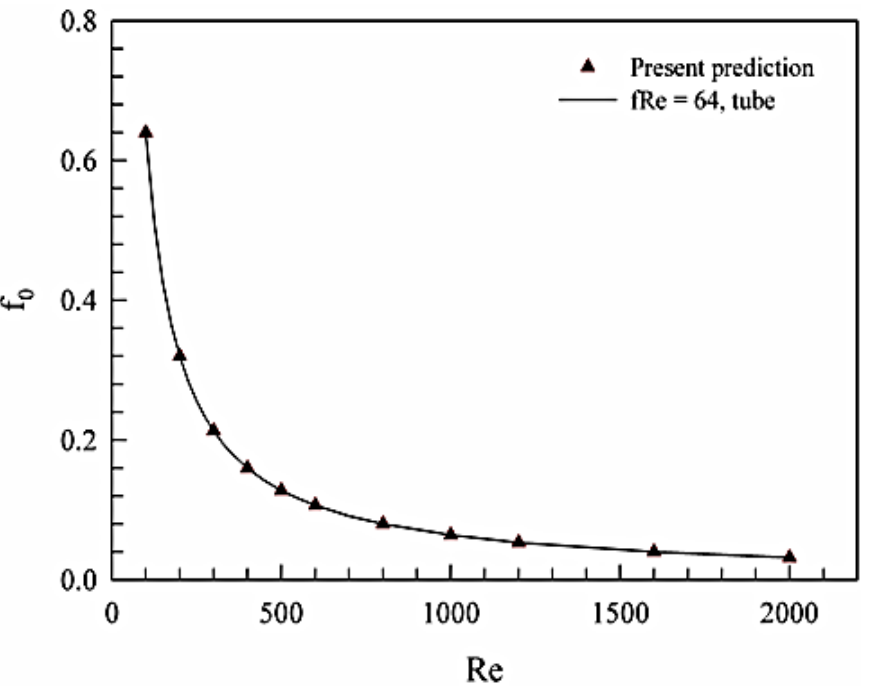

(b)

Fig. 3 Validation of the smooth circular tube for (a) Nusselt number and (b) friction factor.

\section{NUMERICAL RESULT AND DISCUSSION}

This part can divided into four sections; validation with smooth tube, flow configuration, heat transfer characteristic, thermal assessment.

\subsection{Validation with smooth tube}

The validation with the smooth circular tube with no winglet is a very important part to make sure that the current computational domain is reliable to predict the flow and heat transfer behaviors in the tube heat exchanger. The verifications are done by compared the present results with the values from the correlations (Incropera, 2006) on both heat transfer and pressure loss in terms of Nusselt number and friction factor, respectively. Figs. 3a and b present the verifications on Nusselt number and friction factor in the tube heat exchanger with no winglet, respectively. As the figures, there are found that the variations on the Nusselt number and friction factor are around $\pm 0.3 \%$ and $\pm 0.4 \%$, respectively. Therefore, the current computational domain is reliable to investigate the heat transfer and flow configuration in the tube heat exchanger.

\subsection{Flow configuration}

The numerical investigation can help to report the flow structure of the fluid in the tube heat exchanger. The understanding of the flow configuration may be advantageous to develop the new design of the compact heat exchanger. The flow configurations for the circular tube heat exchanger with the punched delta winglet vortex generators $(P D W V G)$ are plotted in terms of tangential velocity vectors and streamlines in transverse planes. 


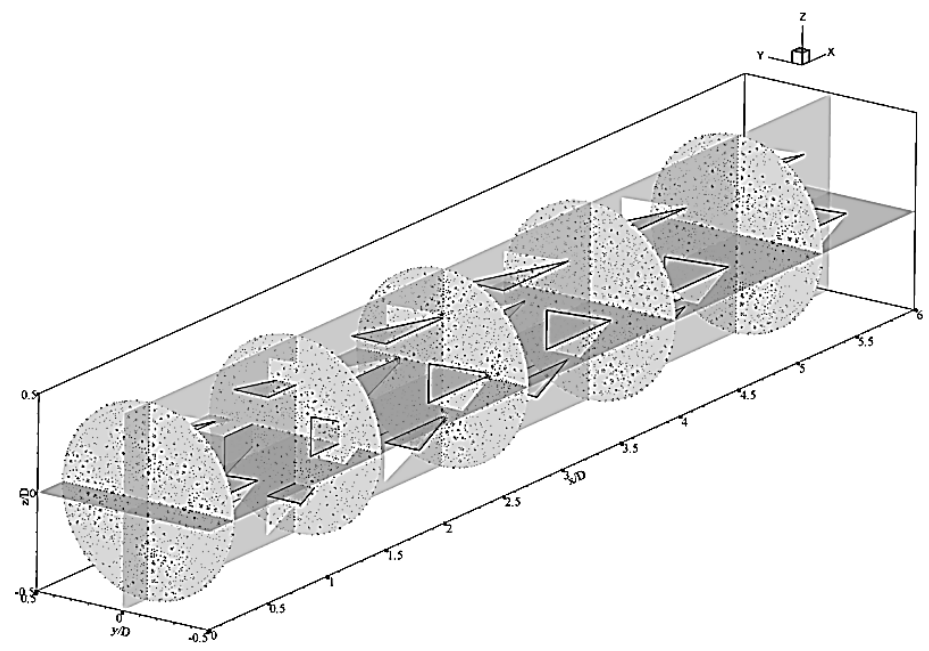

(a)

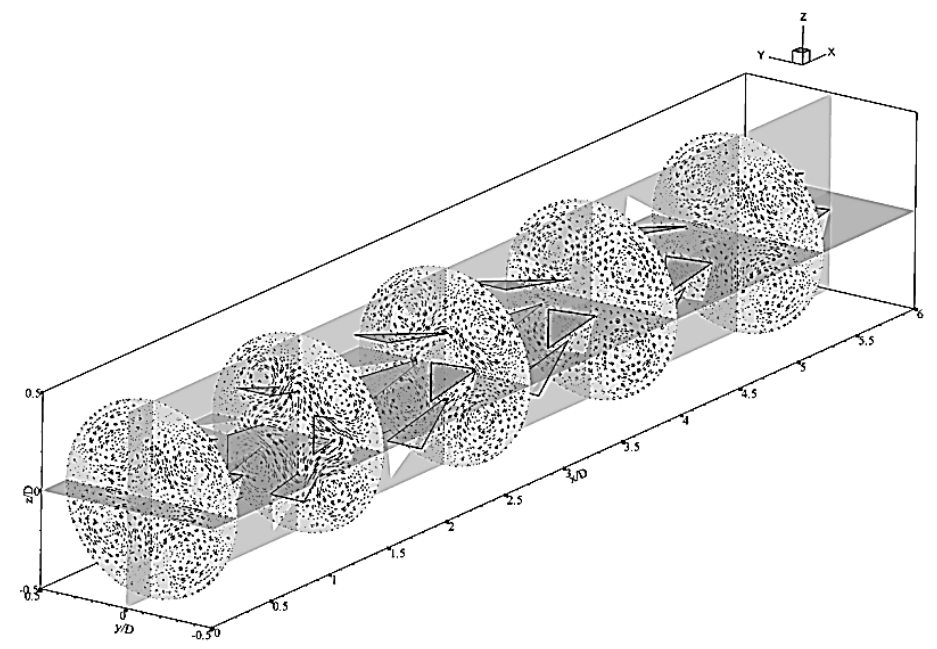

(c)

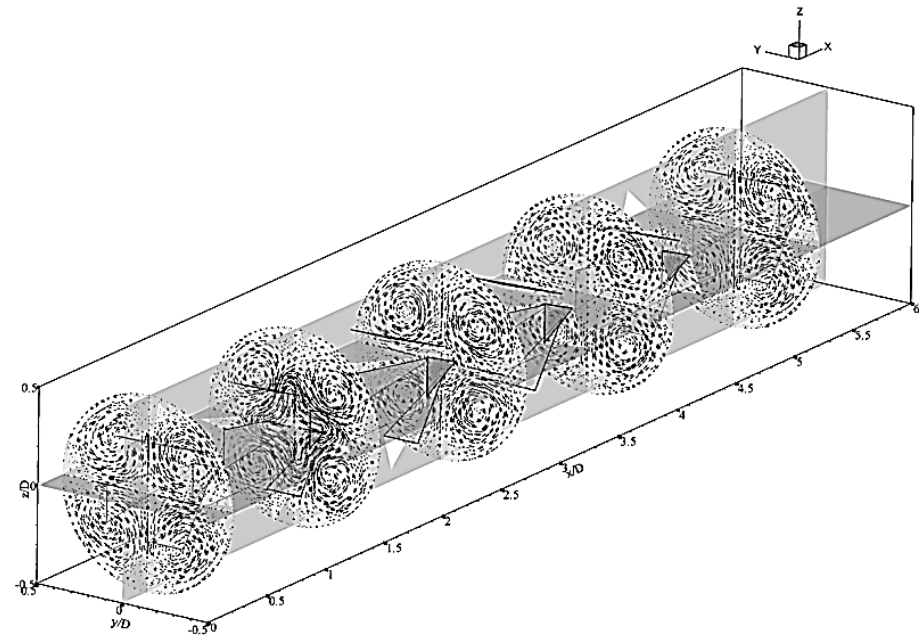

(e)

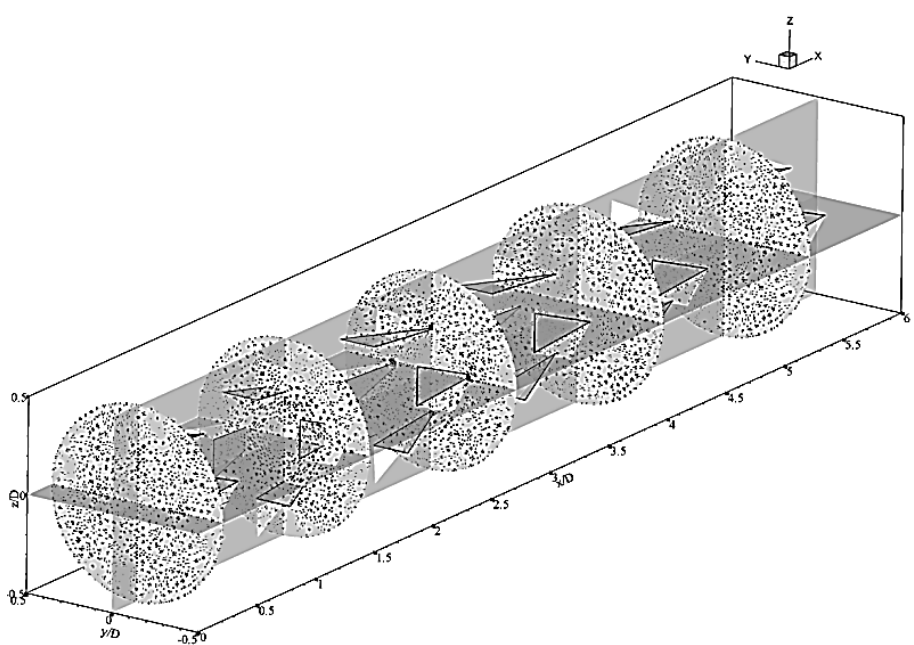

(b)

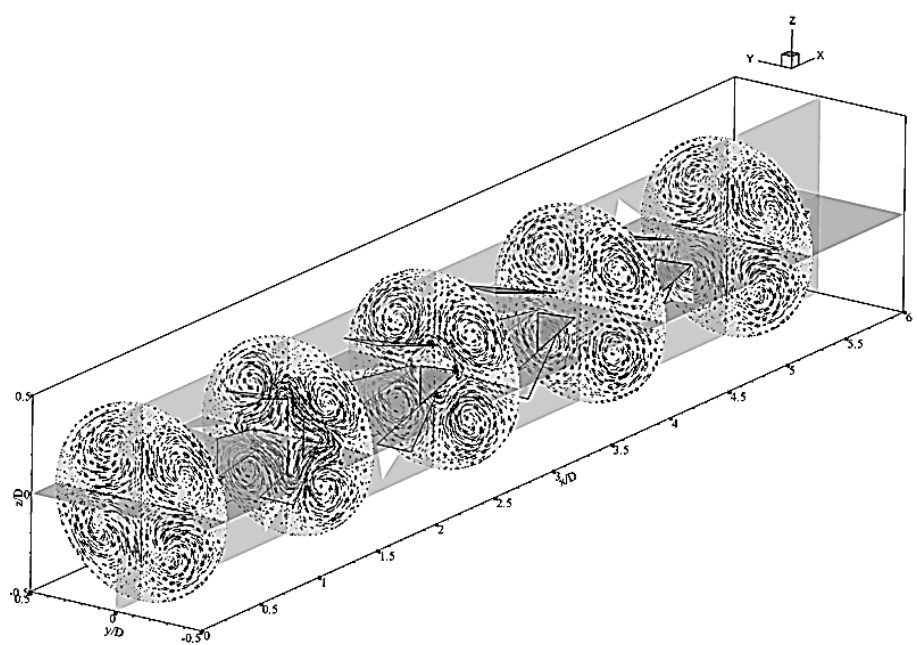

(d)

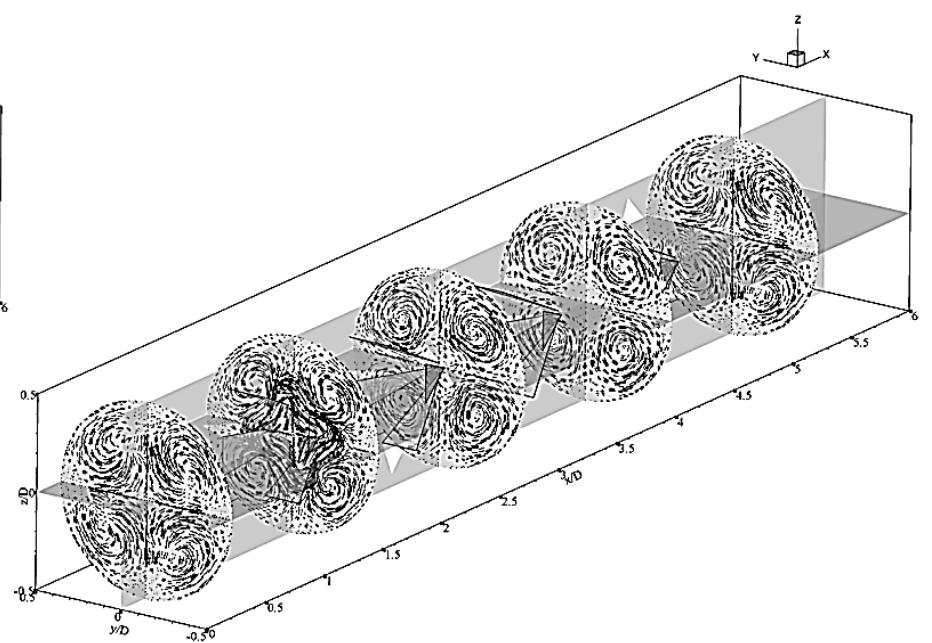

(f)

Fig. 4 The tangential velocity vectors in transverse planes for (a) $0^{\circ}$, (b) $5^{\circ}$, (c) $10^{\circ}$, (d) $15^{\circ}$, (e) $20^{\circ}$ and (f) $25^{\circ}$ of the $P D W V G$ in the tube heat exchanger with winglet tip pointing downstream at $R e=1000$. 


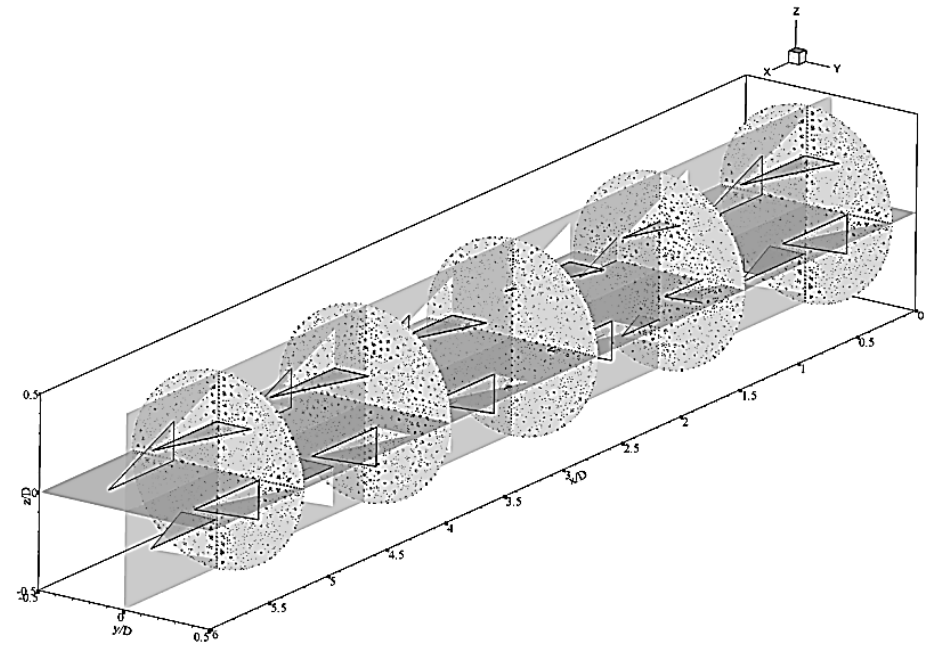

(a)

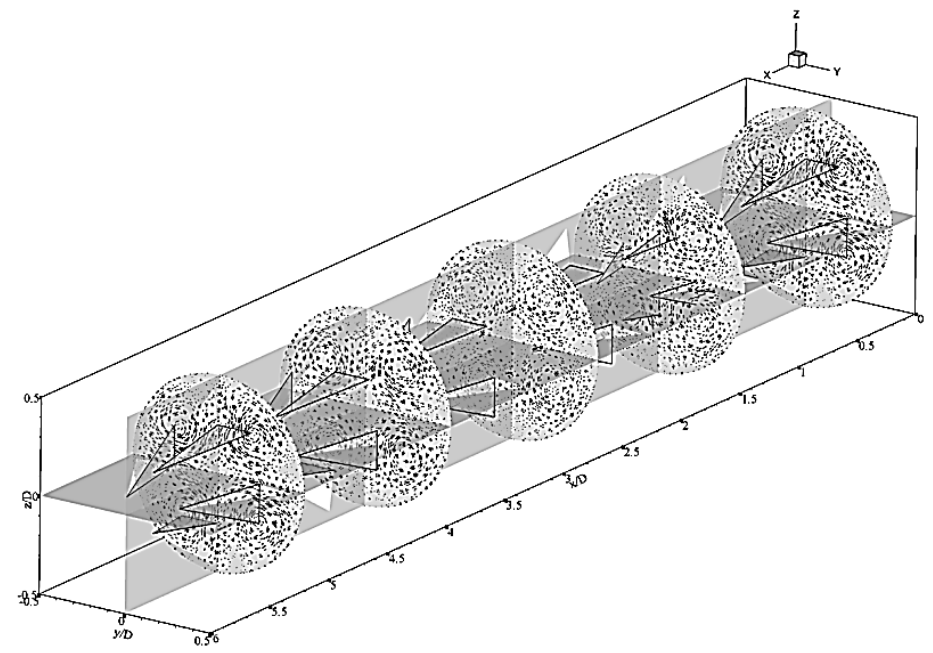

(c)

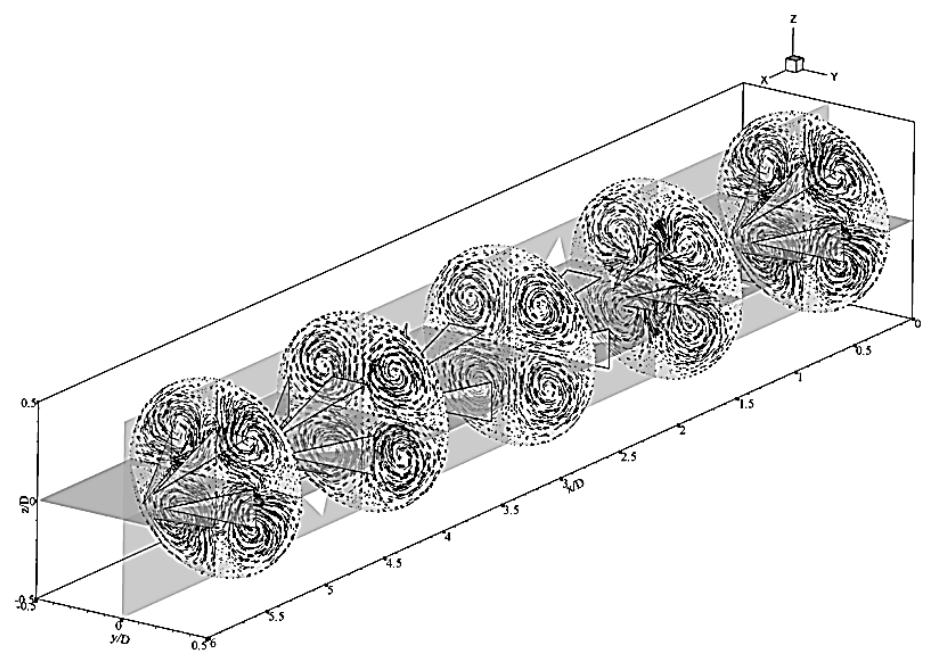

(e)

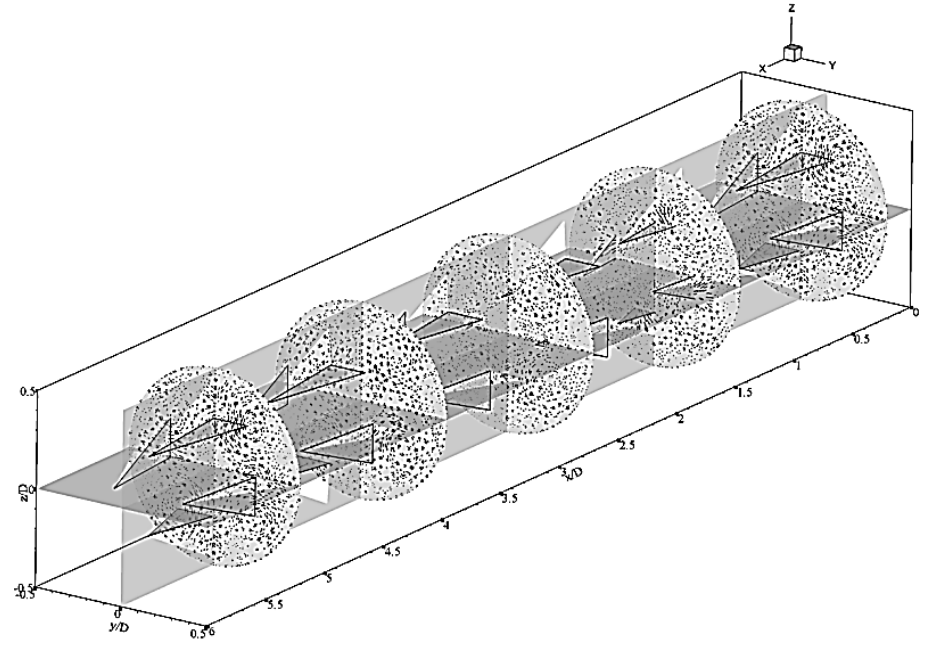

(b)

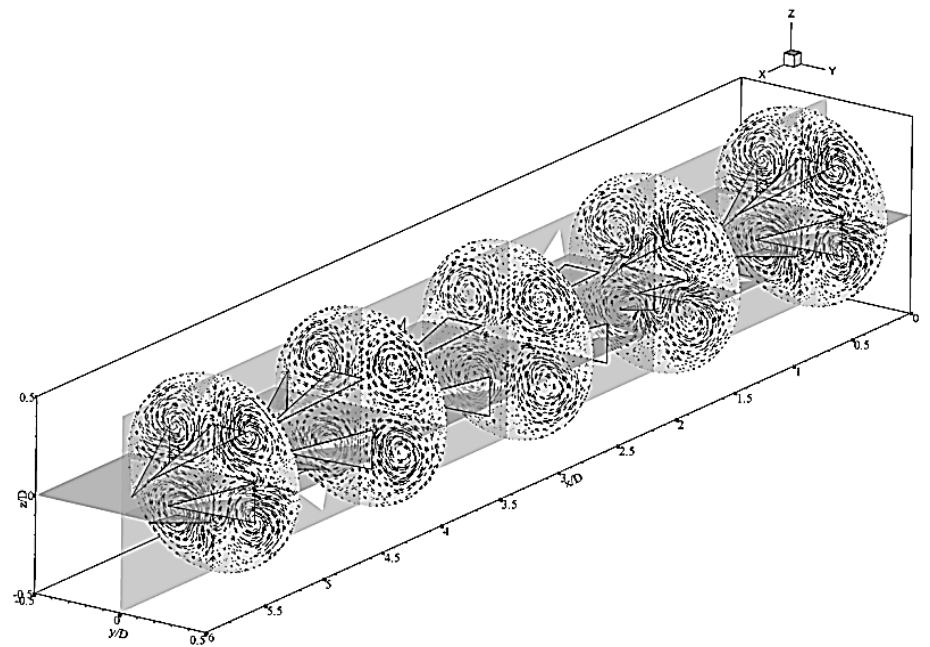

(d)

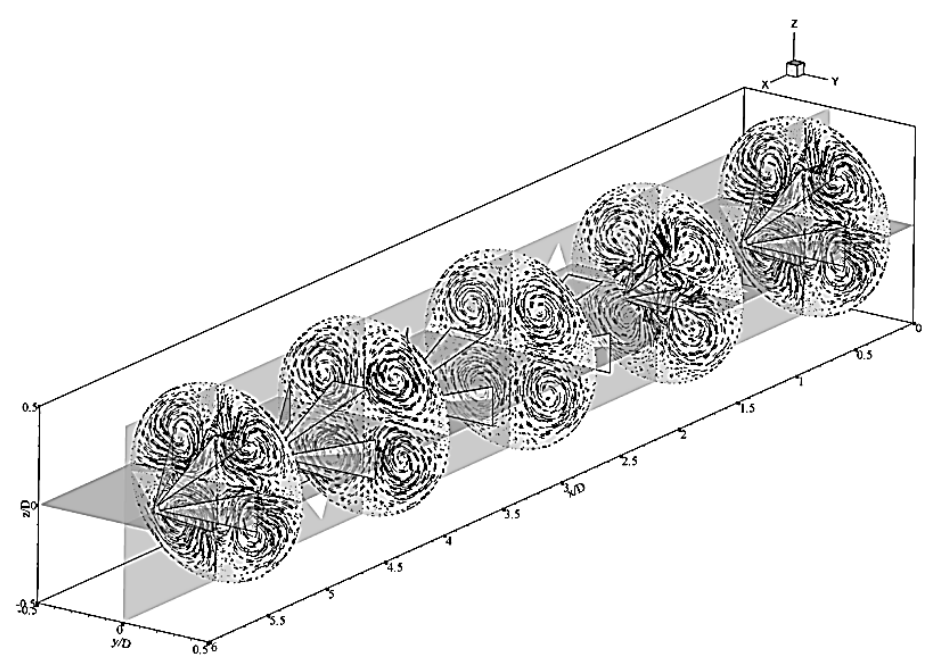

(f)

Fig. 5 The tangential velocity vectors in transverse planes for (a) $0^{\circ}$, (b) $5^{\circ}$, (c) $10^{\circ}$, (d) $15^{\circ}$, (e) $20^{\circ}$ and (f) $25^{\circ}$ of the $P D W V G$ in the tube heat exchanger with winglet tip pointing upstream at $R e=1000$. 

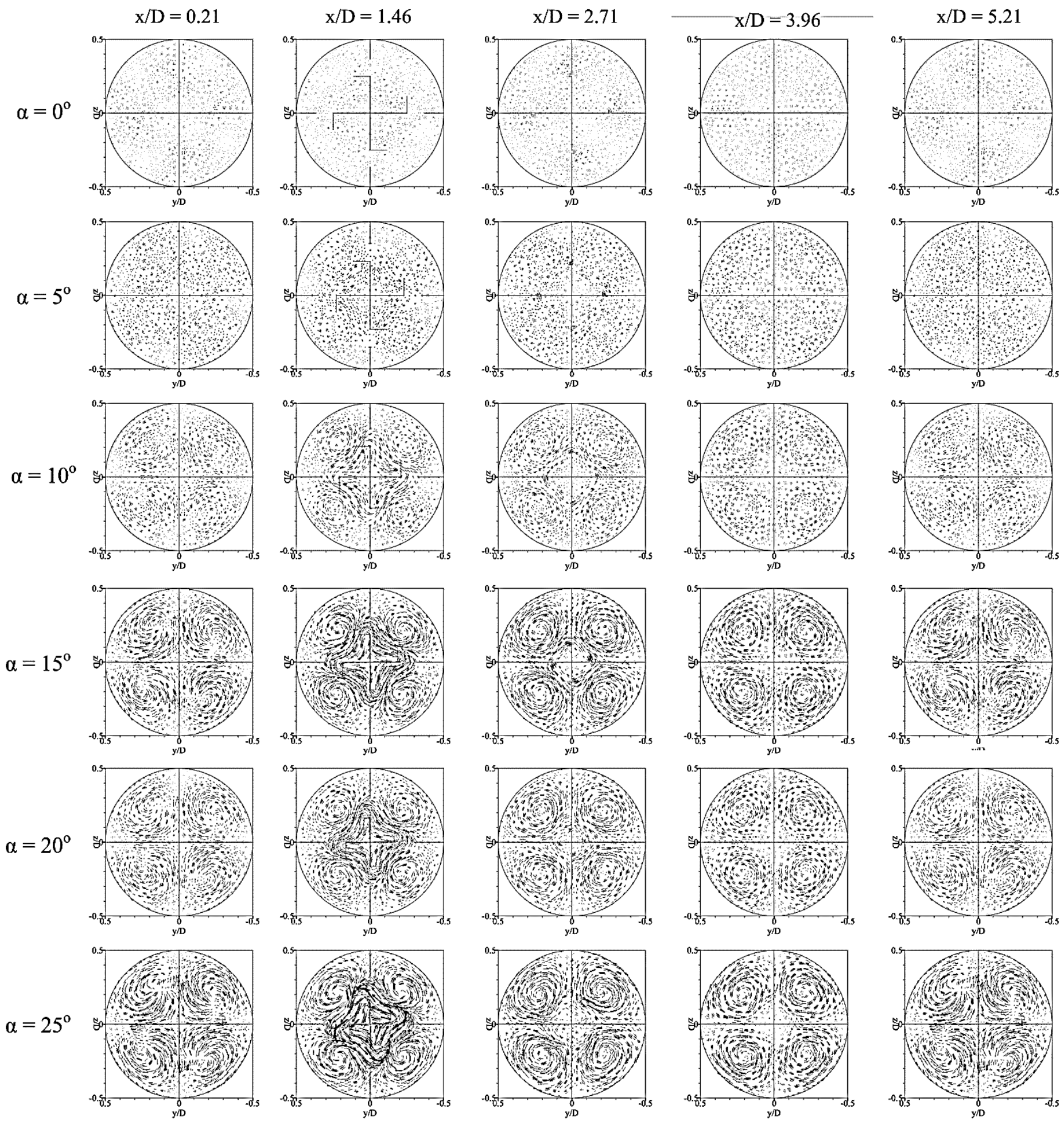

Fig. 6 Details of the tangential velocity vectors in transverse planes at various the flow attack angles for the $P D W V G$ with winglet tip pointing downstream at $R e=1000$. 

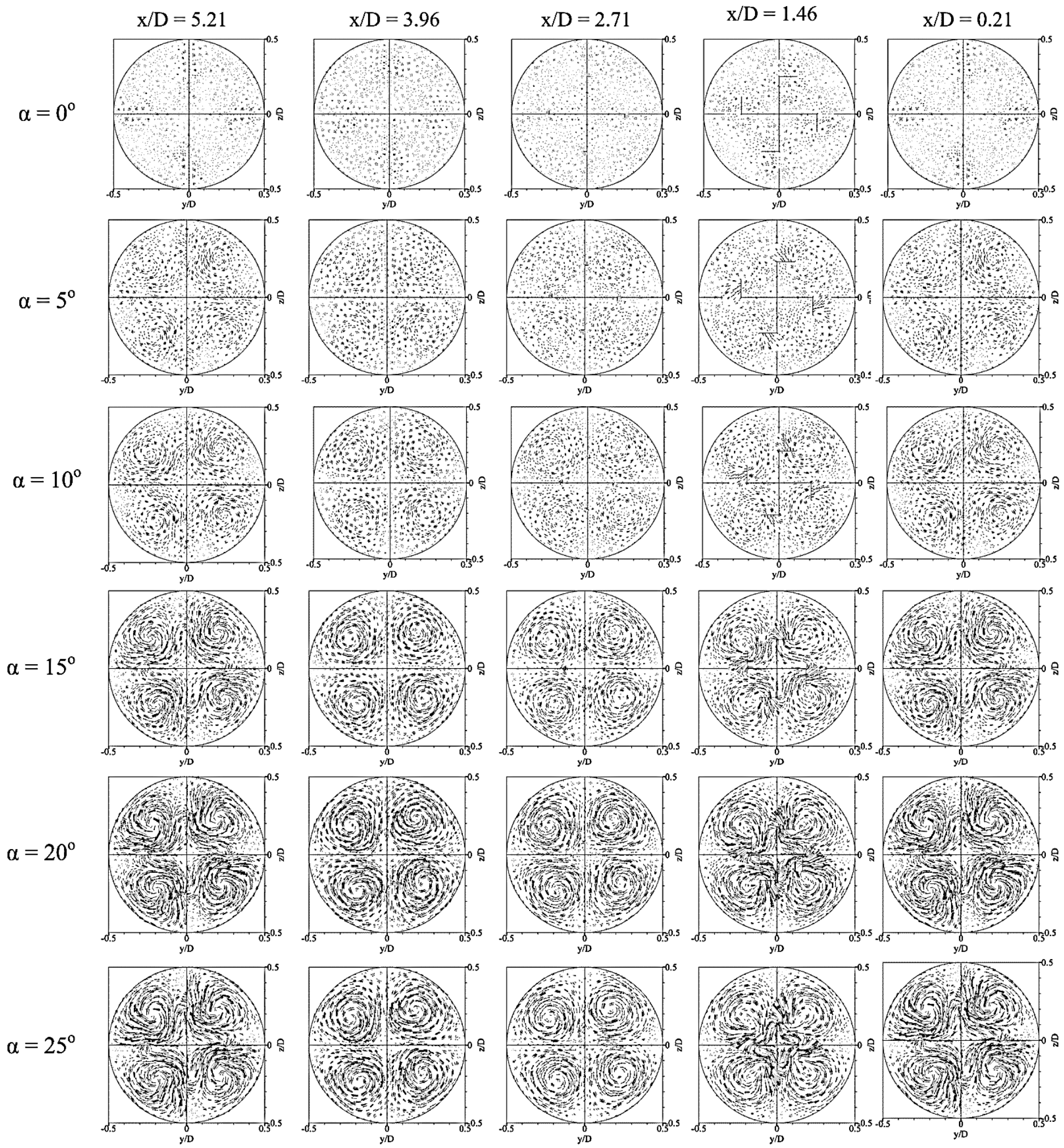

Fig. 7 Details of the tangential velocity vectors in transverse planes at various the flow attack angles for the $P D W V G$ with winglet tip pointing upstream at $R e=1000$. 

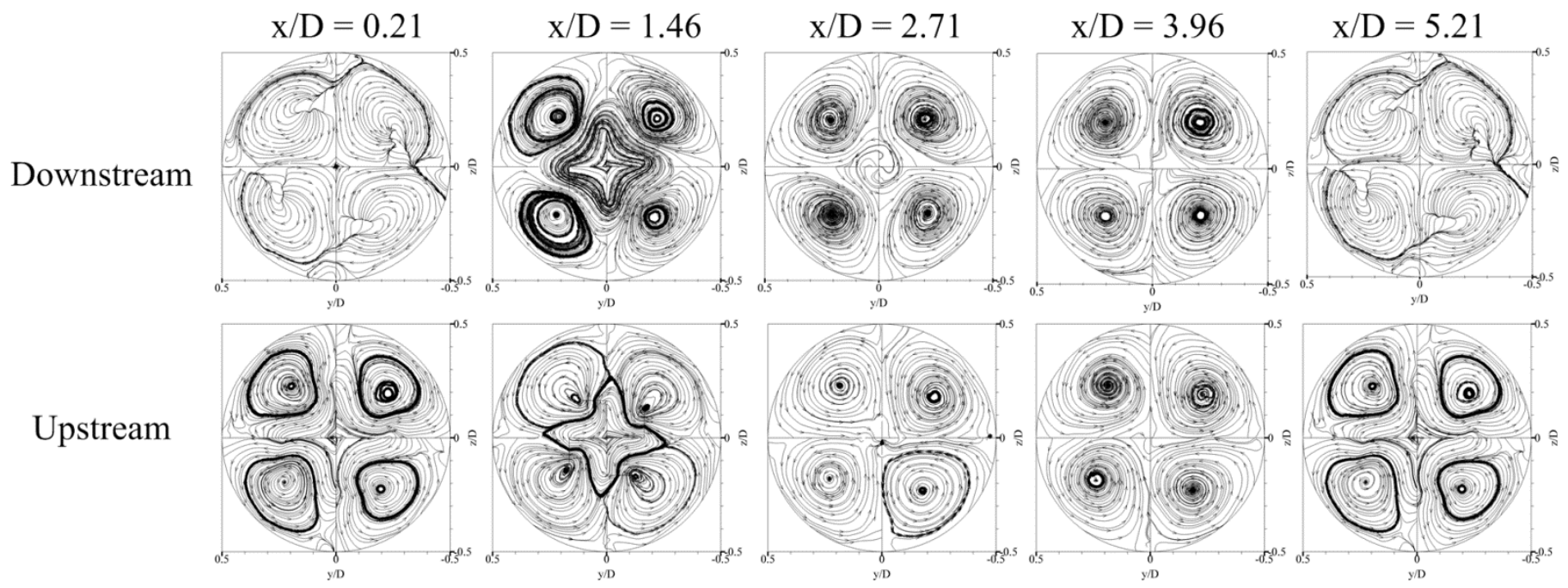

Fig. 8 The streamlines in transverse planes for the $P D W V G$ with winglet tips pointing downstream and upstream at $R e=1000$ and $\alpha=20^{\circ}$.

Figs. $4 a, b, c, d, e$ and $f$ show the tangential velocity vectors in transverse planes of the tube heat exchanger with $P D W V G$ for $\alpha=0^{\circ}$, $5^{\circ}, 10^{\circ}, 15^{\circ}, 20^{\circ}$ and $25^{\circ}$, respectively, at the winglet tip pointing downstream and $R e=1000$. As the figure, the tangential velocity vectors are found clearly when the flow attack angle is higher than $15^{\circ}$. The flow attack angles of $10^{\circ}$ and $15^{\circ}$ can create slightly tangential velocity vectors, while the tangential velocity vectors are not found in the flow attack angle of $0^{\circ}$. The tangential velocity vectors are representative of the vortex flow, which are generated by the $P D W V G$. The vortex flows lead to a better mixing of the fluid flow and help to improve the heat transfer rate and thermal performance in the heat exchanger. The similar results are found when using $P D W V G$ at the winglet tip pointing upstream as the Figs. $5 a, b, c, d, e$ and $f$ for $\alpha=0^{\circ}$, $5^{\circ}, 10^{\circ}, 15^{\circ}, 20^{\circ}$ and $25^{\circ}$, respectively, $R e=1000$. The details of the tangential velocity vectors in transverse planes at different locations for the winglet tip pointing downstream and upstream are presented in Figs. 6 and 7 , respectively.

Fig. 8 shows the streamlines in transverse planes for the $20^{\circ}$ $P D W V G$ inserted in the tube heat exchanger with the winglet tips pointing downstream and upstream at various locations and $R e=1000$. It is found that the use of the $P D W V G$ can generate the four main vortex flows on both cases. The winglet tip pointing downstream gives the clockwise vortex flow, while the winglet tip pointing upstream provides the counter clockwise vortex flow.

\subsection{Heat transfer characteristic}

The temperature distributions in transverse planes and the local Nusselt number distributions on the tube wall are used to present the heat transfer behaviors in the tube heat exchanger when installing with $P D W V G$. Figs. $9 a, b, c, d, e$ and $f$ present the temperature distributions in transverse planes for the $P D W V G$ in the tube heat exchanger with $\alpha$ $=0^{\circ}, 5^{\circ}, 10^{\circ}, 15^{\circ}, 20^{\circ}$ and $25^{\circ}$, respectively, at $R e=1000$. In general, the use of the $P D W V G$ provides a better mixing of the fluid flow between near the tube wall and the core of the test section for all the flow attack angles. Considering at the red layer of the temperature contours near the tube wall, the red layer tends to decrease when increasing the flow attack angles. The flow attack angle of $0^{\circ}$ performs the lowest performance of the fluid mixing, while the flow attack angle of $25^{\circ}$ provides the best result. The similar trends of the numerical results are found when using the $P D W V G$ with the tip pointing upstream as depicted in the Fig.10. The details for each plane of the temperature distributions on both tips pointing downstream and upstream with various locations are reported in the Figs. 11 and 12, respectively, at $R e=1000$.

Figs. $13 a, b, c, d, e$ and $f$ present the local Nusselt number distributions on the tube wall of $P D W V G$ in the tube heat exchanger for $\alpha=0^{\circ}, 5^{\circ}, 10^{\circ}, 15^{\circ}, 20^{\circ}$ and $25^{\circ}$, respectively, at $R e=1000$ and the winglet tip pointing downstream. There are clearly seen in the figures that the rise of the flow attack angle leads to increase in the Nusselt number. The flow attack angle of $25^{\circ}$ gives the highest heat transfer rate, while the flow attack angle of $0^{\circ}$ performs the lowest value. The $P D W V G$ s with winglet tip pointing upstream, which plots in the Fig. 14 , are performed the related results as the winglet tip pointing downstream for all the flow attack angles. The peaks of heat transfer regimes; red contours of Nusselt number, for both cases are found similarly.

In addition, the flow configuration and heat transfer characteristic in the tube heat exchanger with $P D W V G$ s are found to be related. The enhancement of the heat transfer rate is due to the vortex flows that generated from the $P D W V G$ s on both the tips pointing downstream and upstream.

\subsection{Thermal performance assessment}

The thermal performance assessments in the current investigations are plotted as Figs $15-17$. The heat transfer rate, pressure loss and performance in the tube heat exchanger with $P D W V G$ s are presented in terms of the Nusselt number ratio $\left(N u / N u_{0}\right)$, friction factor ratio $\left(f / f_{0}\right)$, and thermal enhancement factor $(T E F)$, respectively.

Figs. $15 a$ and $b$ present the variations of the $N u / N u_{0}$ with the Reynolds number at various the flow attack angles for the winglet tips pointing downstream and upstream, respectively. In general, the $N u / N u 0$ tends to increase with the rise of the Reynolds number and flow attack angles on both cases. The $N u / N u$ for all the flow attack angles of the winglet tip pointing downstream performs nearly values as the winglet tip pointing upstream. The flow attack angle of $25^{\circ}$ gives the highest $N u / N u 0$, while the flow attack angle of $0^{\circ}$ performs the lowest heat transfer rate on both downstream and upstream cases. The flow attack angle of $25^{\circ}$ gives the maximum higher $N u / N u_{0}$ than the flow attack angle of $0^{\circ}, 5^{\circ}, 10^{\circ}, 15^{\circ}$, and $20^{\circ}$ around $54.36 \%, 35.34 \%, 20.29 \%, 13 \%$ and $6.81 \%$, respectively, at $R e=2000$. In range studies, the use of the $P D W V G$ in the tube heat exchanger gives the Nusselt number higher than the smooth tube with no $P D W V G$ around $1.6-6.31$ times. 


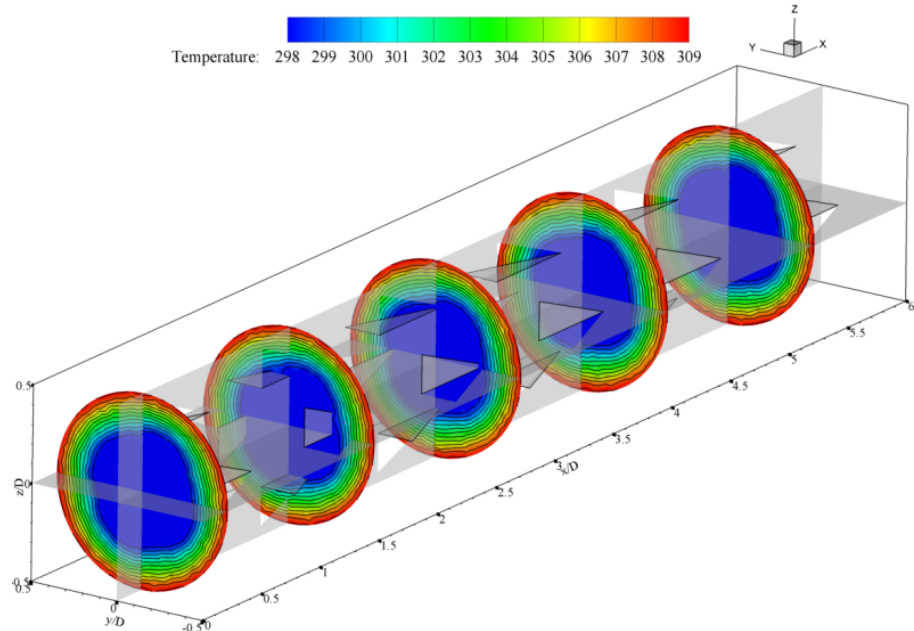

(a)

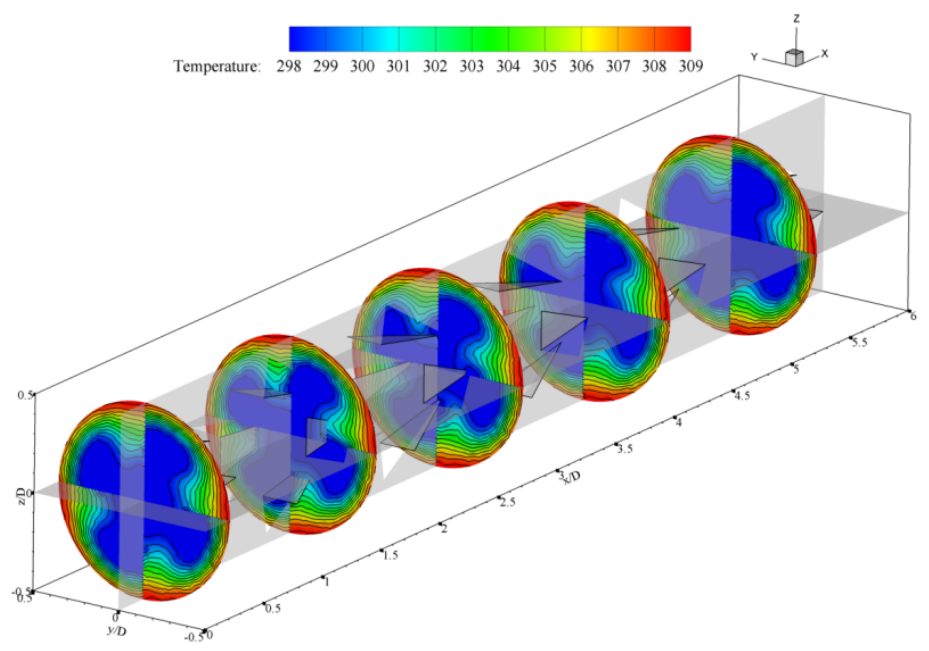

(c)

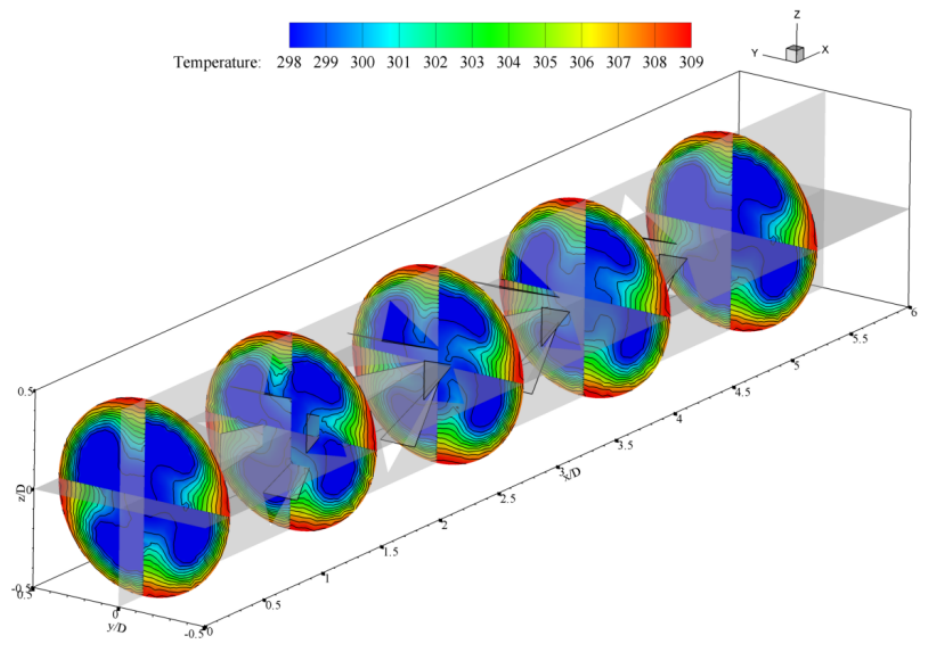

(e)

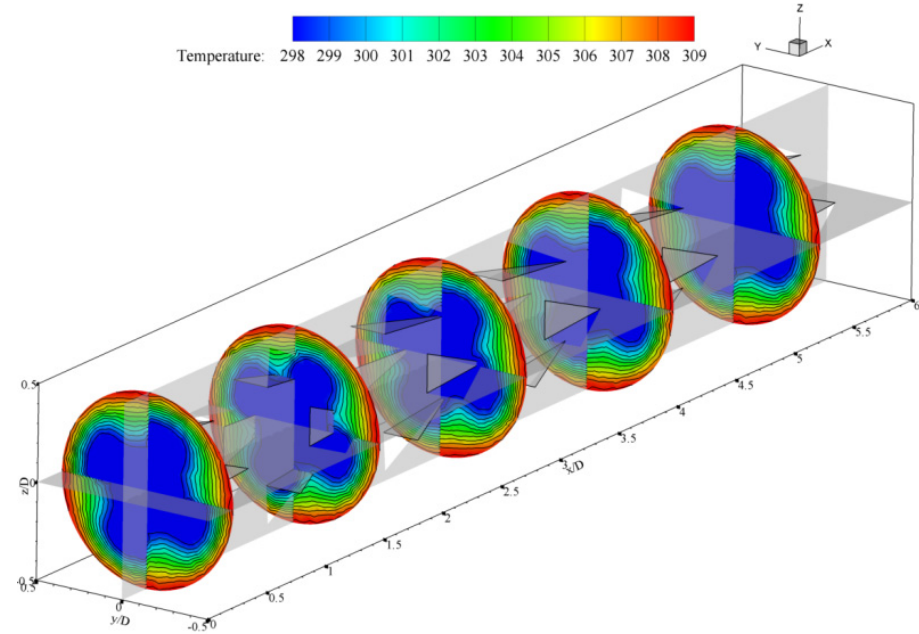

(b)

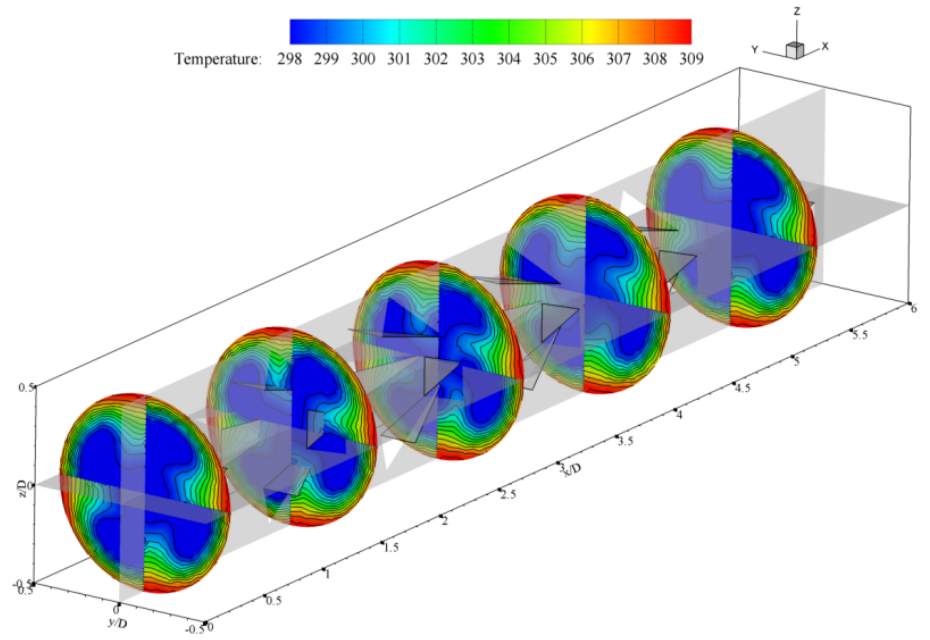

(d)

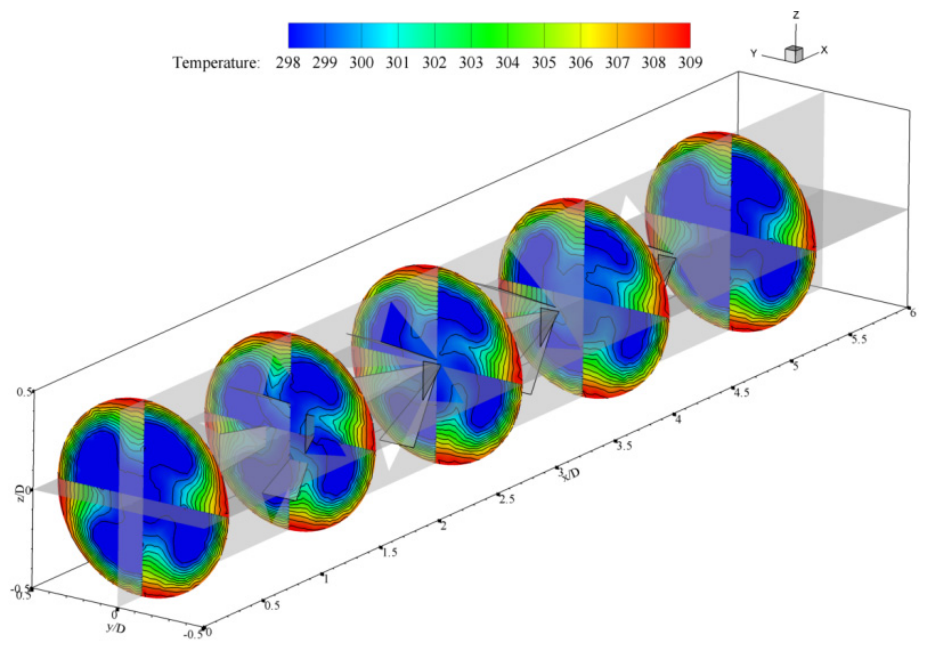

(f)

Fig. 9 The temperature distributions in transverse planes for (a) $0^{\circ}$, (b) $5^{\circ}$, (c) $10^{\circ}$, (d) $15^{\circ}$, (e) $20^{\circ}$ and (f) $25^{\circ}$ of the $P D W V G$ in the tube heat exchanger with winglet tip pointing downstream at $R e=1000$. 


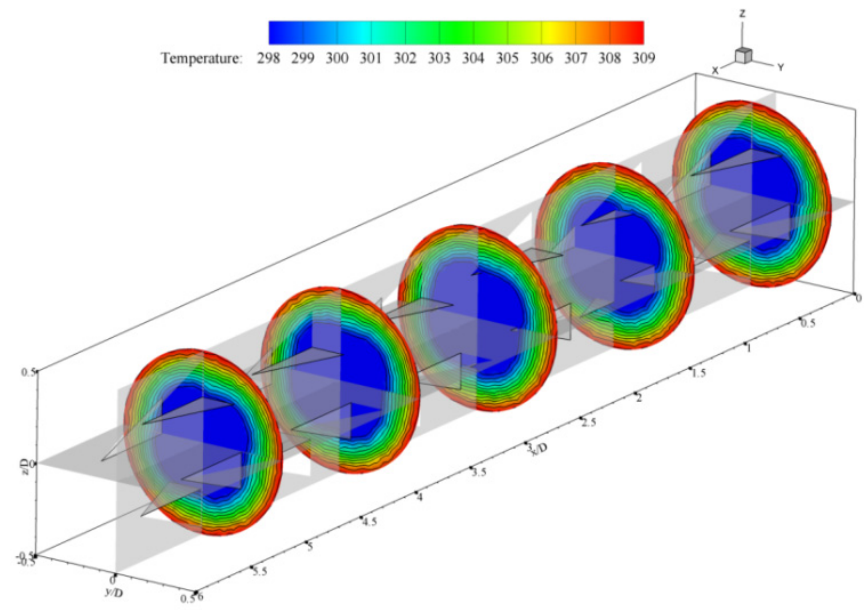

(a)

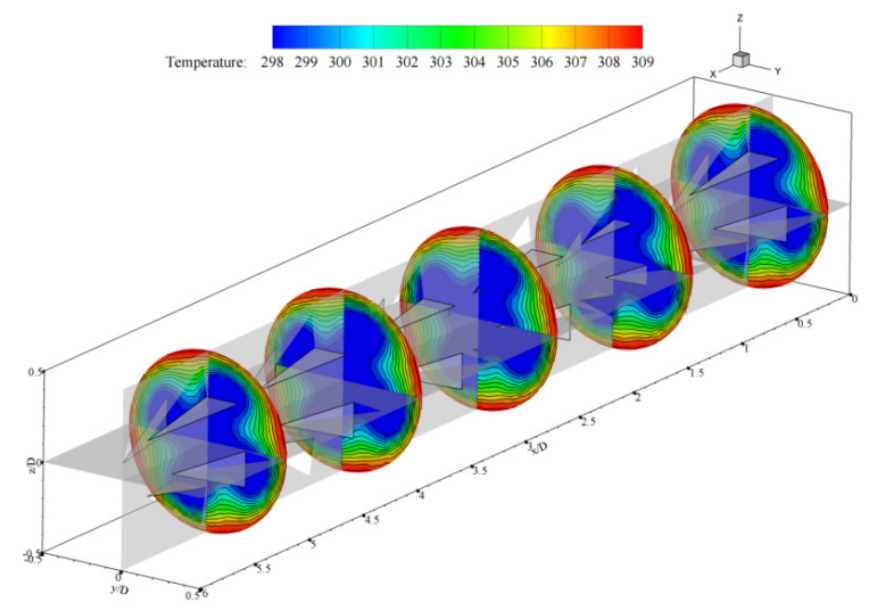

(c)

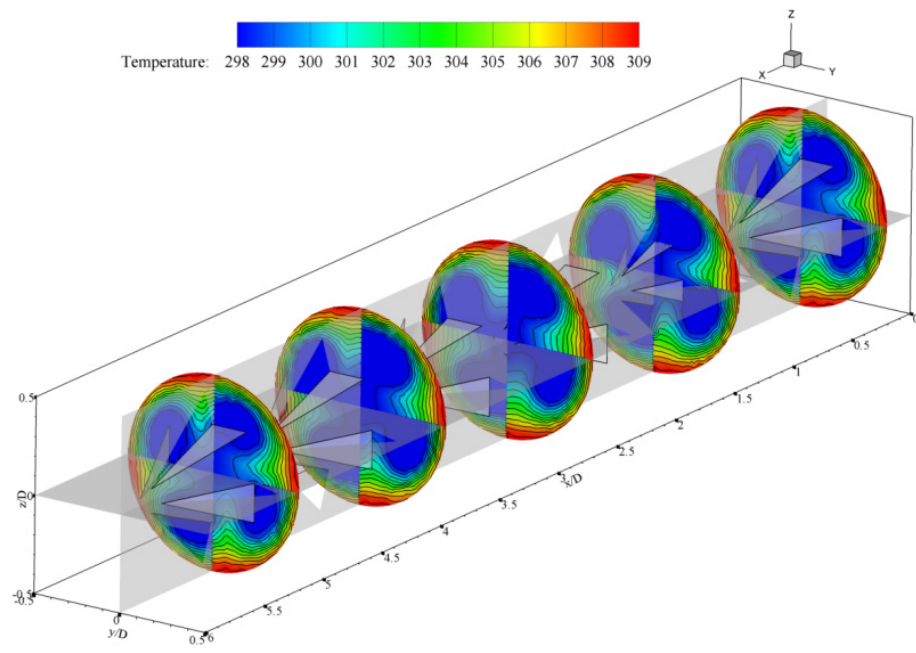

(e)

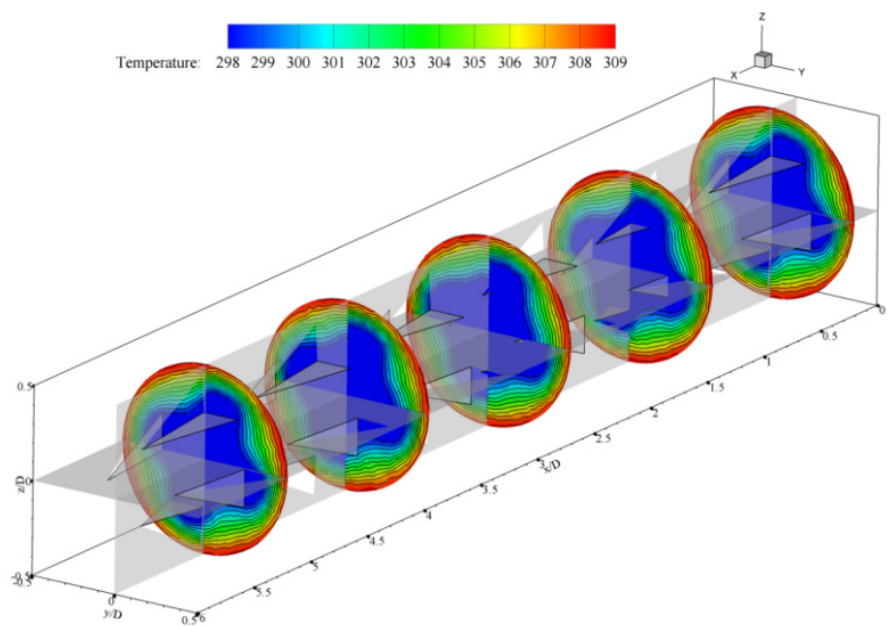

(b)

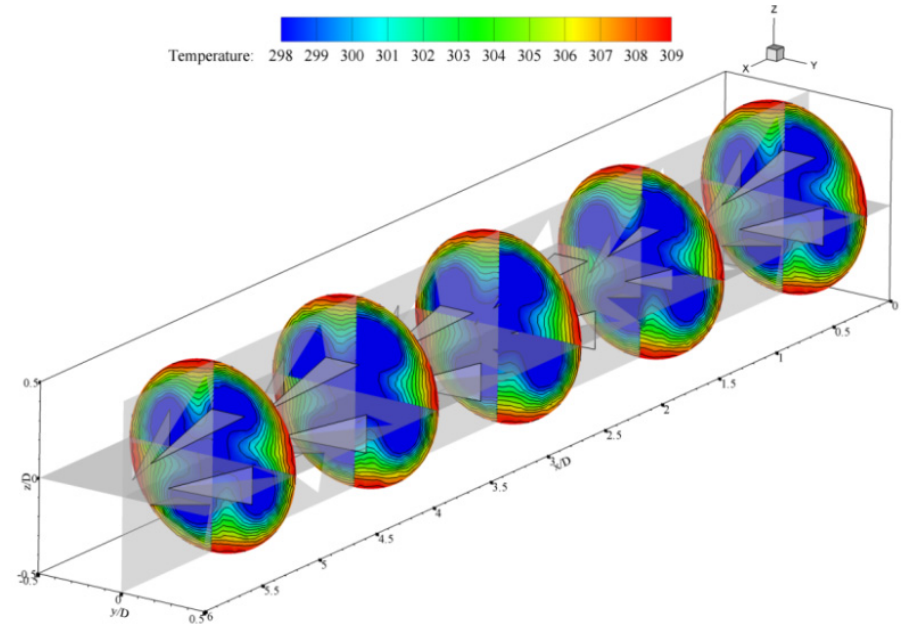

(d)

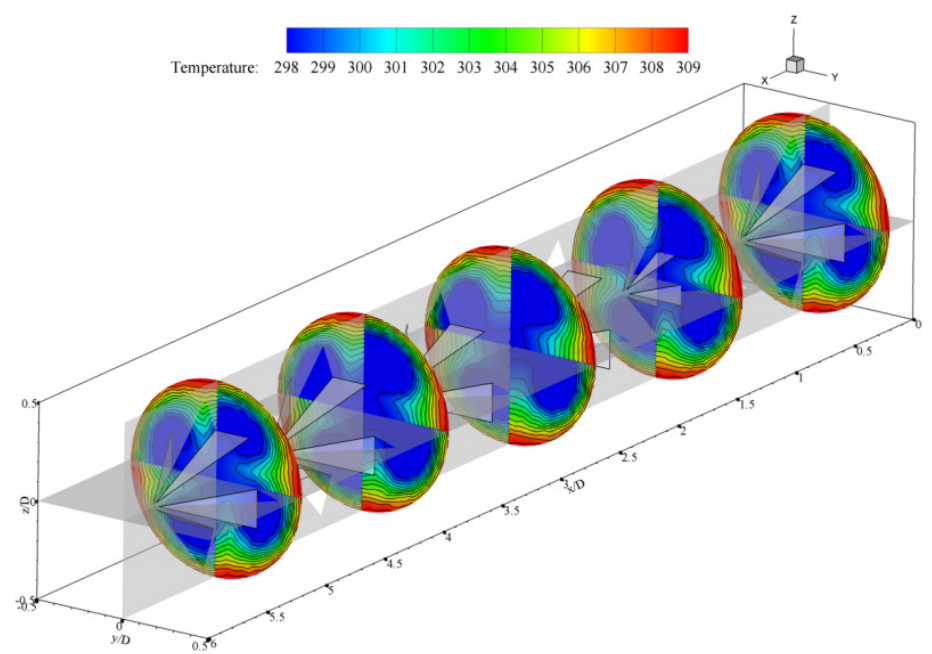

(f)

Fig. 10 The temperature distributions in transverse planes for (a) $0^{\circ}$, (b) $5^{\circ}$, (c) $10^{\circ}$, (d) $15^{\circ}$, (e) $20^{\circ}$ and (f) $25^{\circ}$ of the $P D W V G$ in the tube heat exchanger with winglet tip pointing upstream at $R e=1000$. 

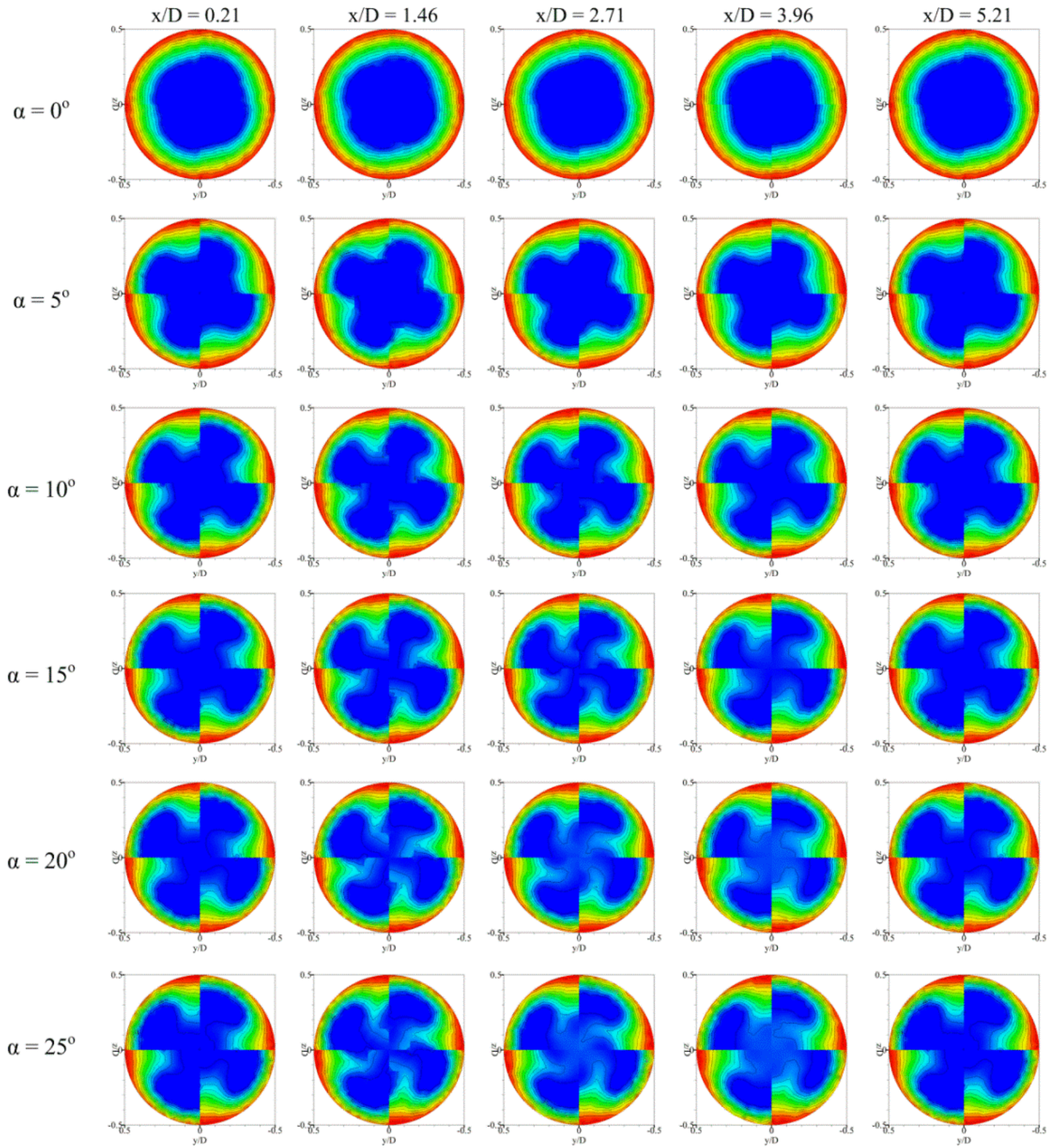

Fig. 11 The details of the temperature distributions in transverse planes at various the flow attack angles for the $P D W V G$ with winglet tip pointing downstream at $R e=1000$. 

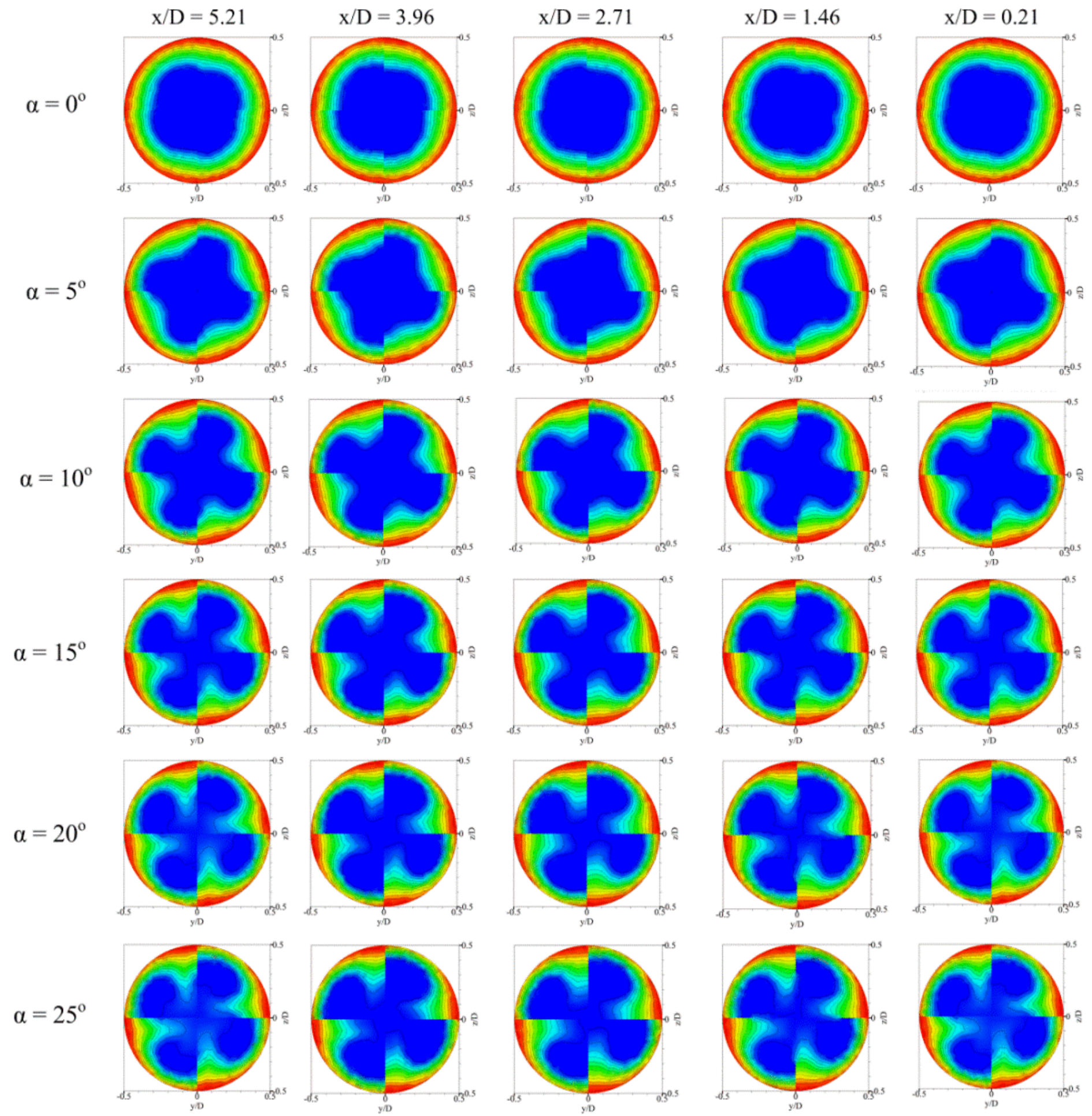

Fig. 12 The details of the temperature distributions in transverse planes at various the flow attack angles for the $P D W V G$ with winglet tip pointing upstream at $R e=1000$. 


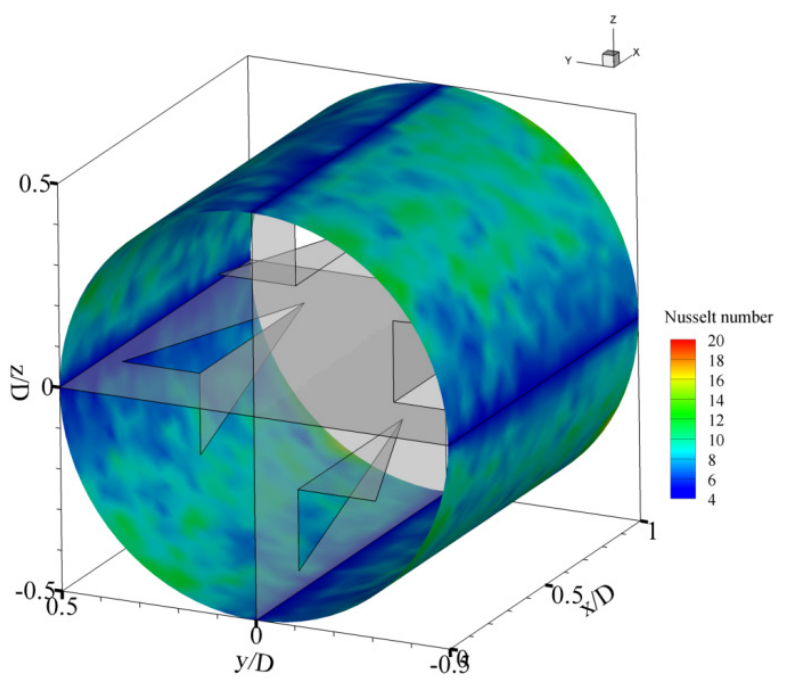

(a)

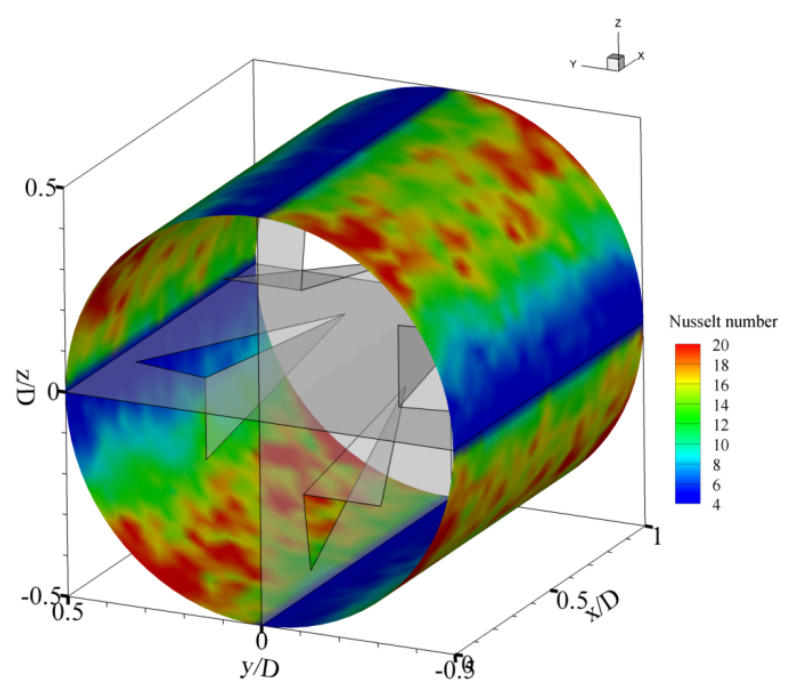

(c)

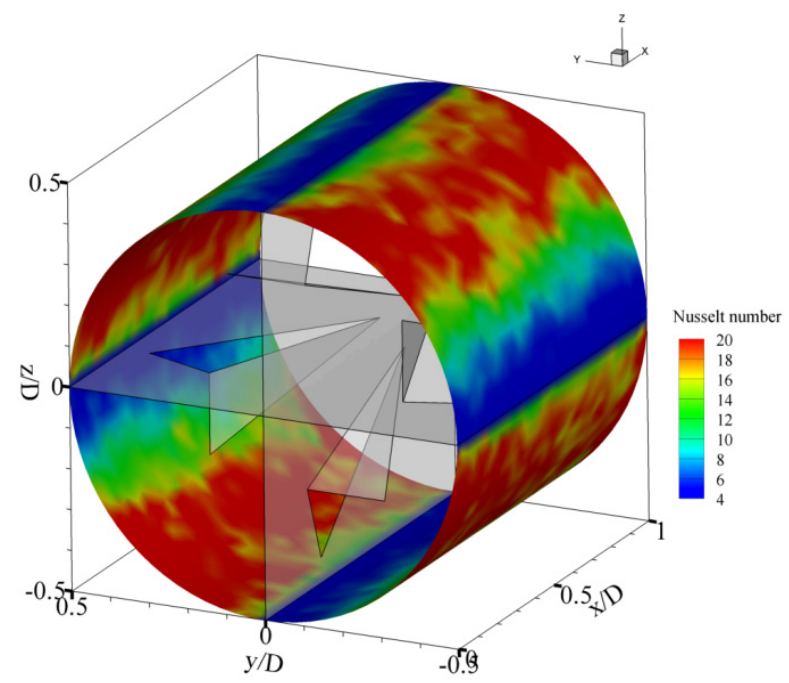

(e)

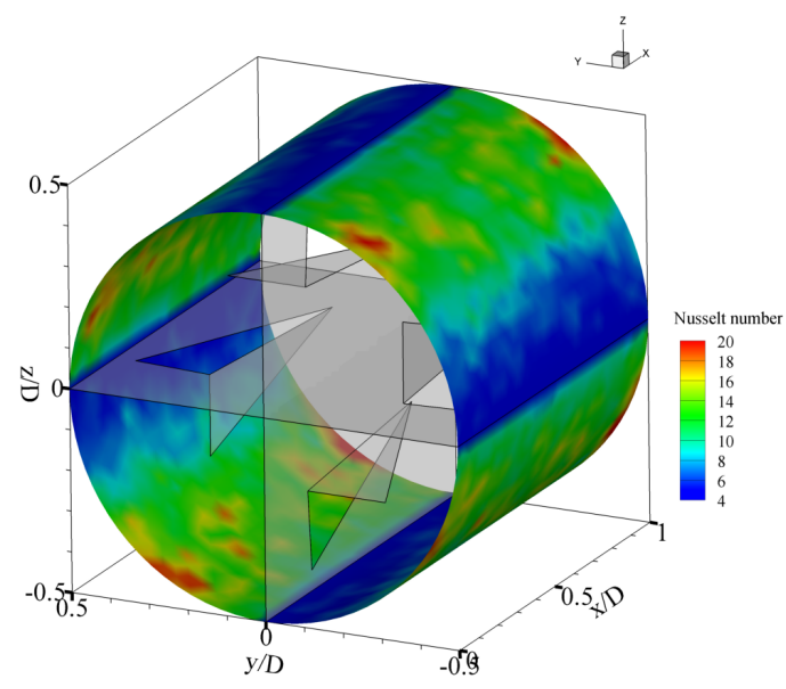

(b)

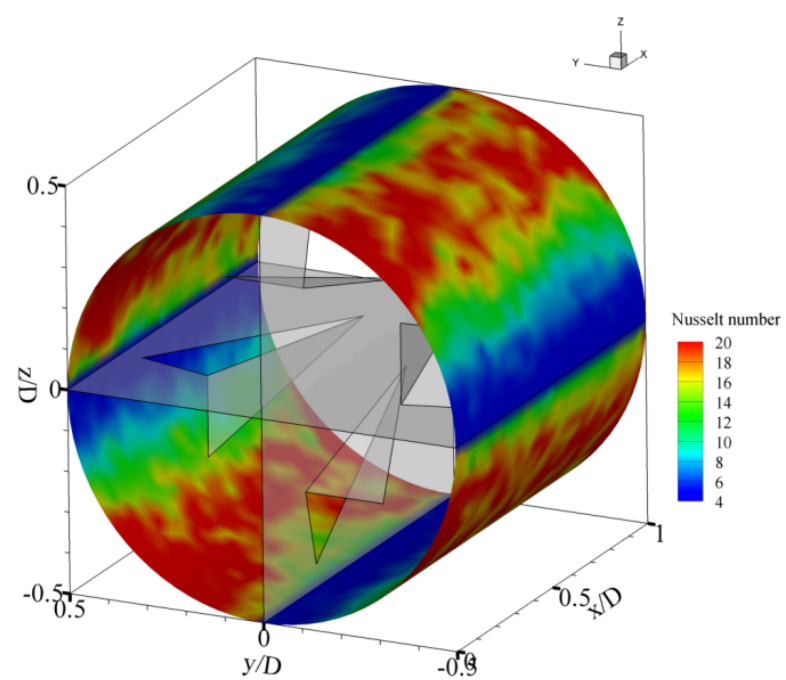

(d)

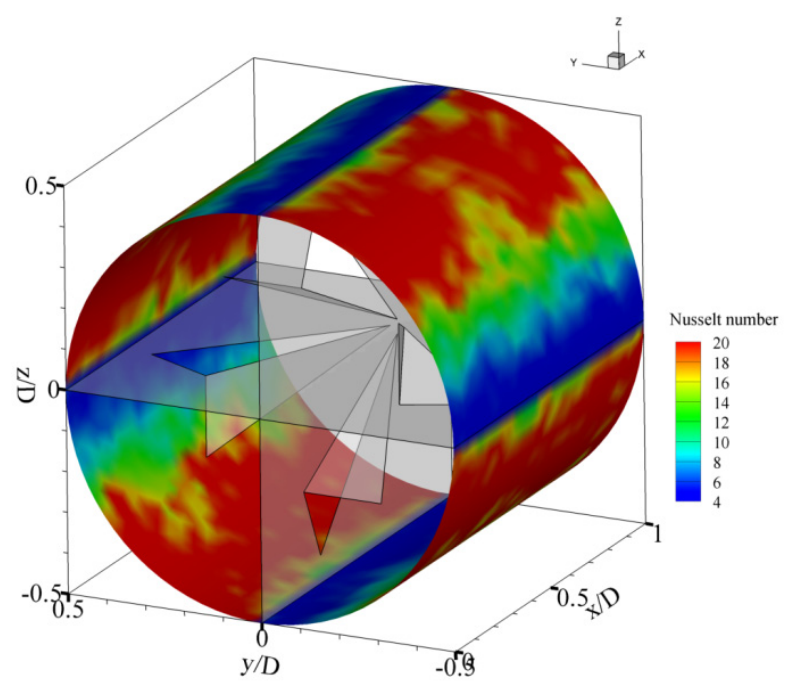

(f)

Fig. 13 The local Nusselt number distributions in transverse planes for (a) $0^{\circ}$, (b) $5^{\circ}$, (c) $10^{\circ}$, (d) $15^{\circ}$, (e) $20^{\circ}$ and (f) $25^{\circ}$ of the $P D W V G$ in the tube heat exchanger with winglet tip pointing downstream at $R e=1000$. 


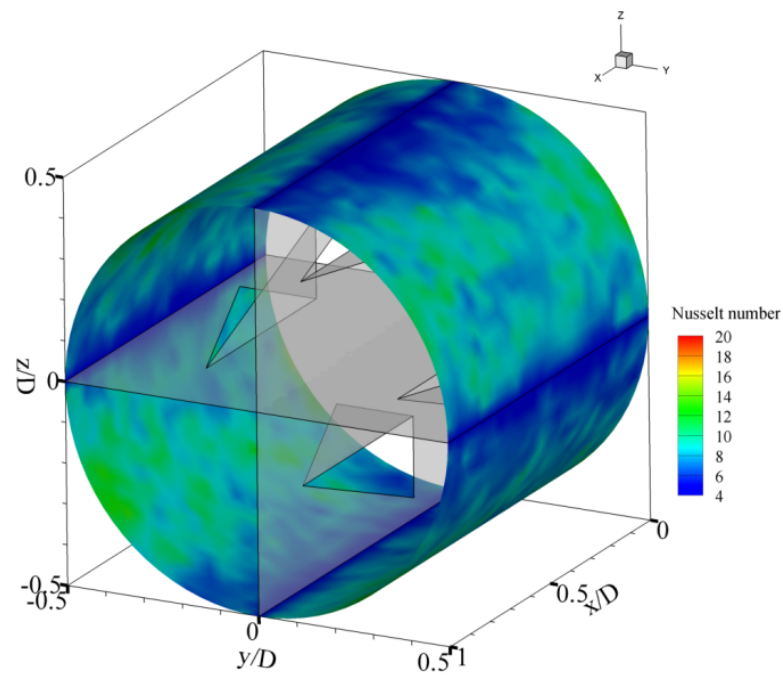

(a)

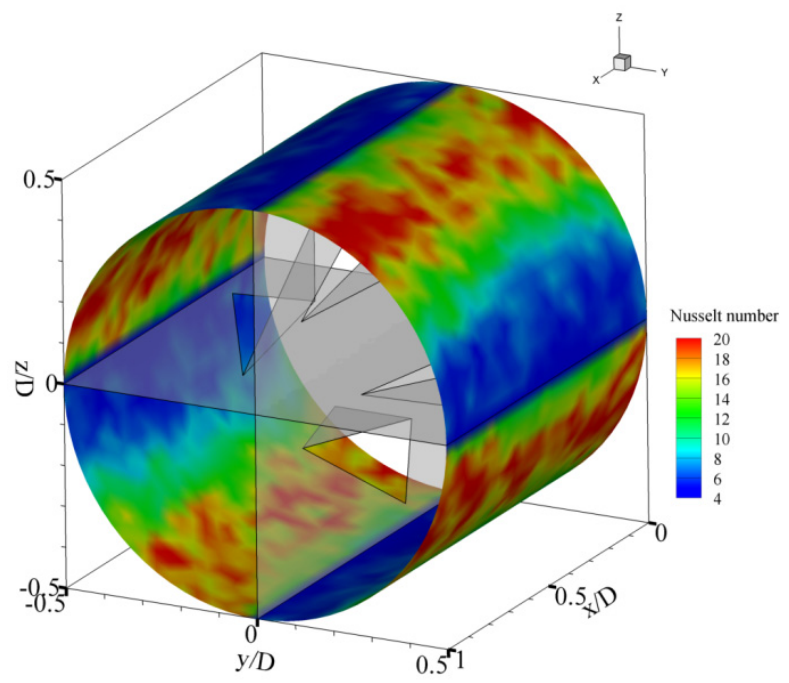

(c)

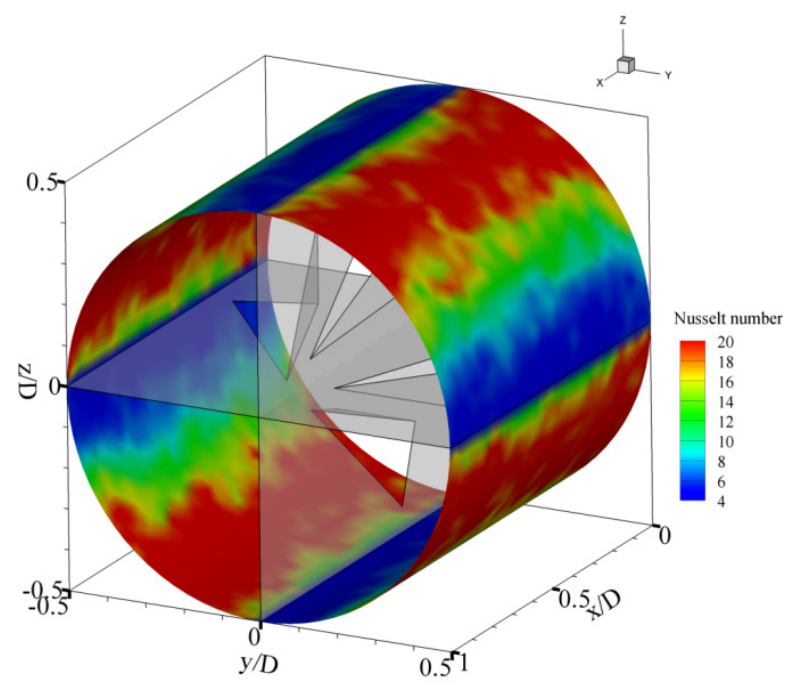

(e)

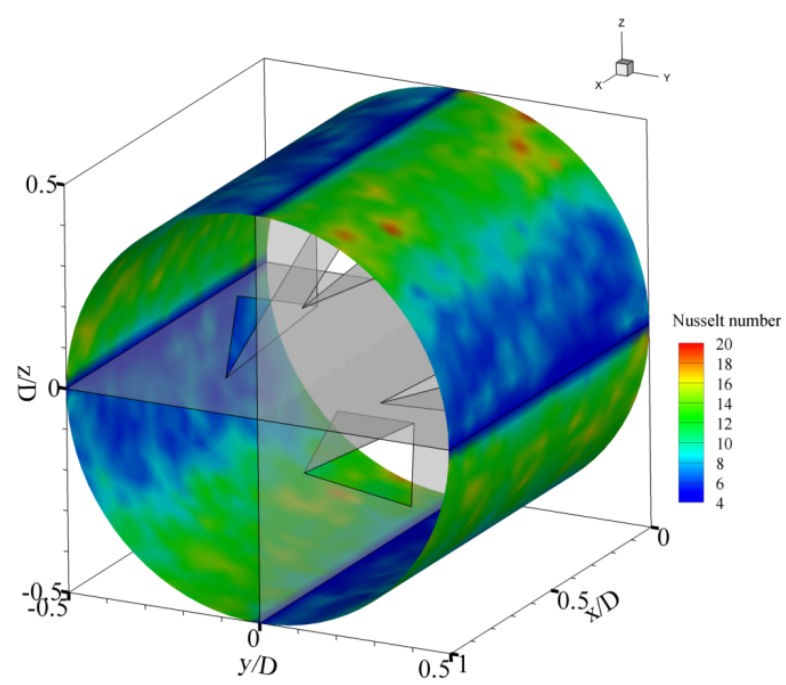

(b)

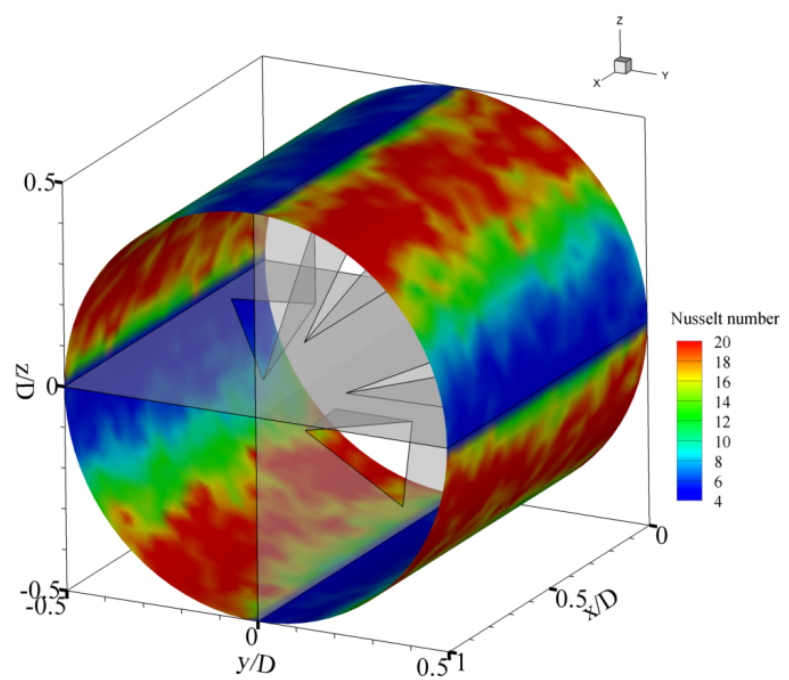

(d)

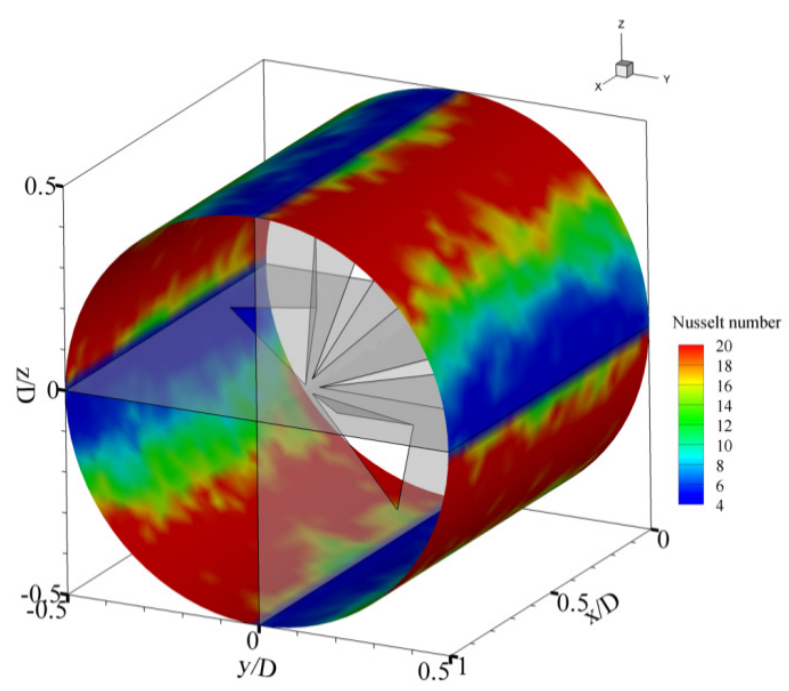

(f)

Fig. 14 The local Nusselt number distributions in transverse planes for (a) $0^{\circ}$, (b) $5^{\circ}$, (c) $10^{\circ}$, (d) $15^{\circ}$, (e) $20^{\circ}$ and (f) $25^{\circ}$ of the $P D W V G$ in the tube heat exchanger with winglet tip pointing upstream at $R e=1000$. 


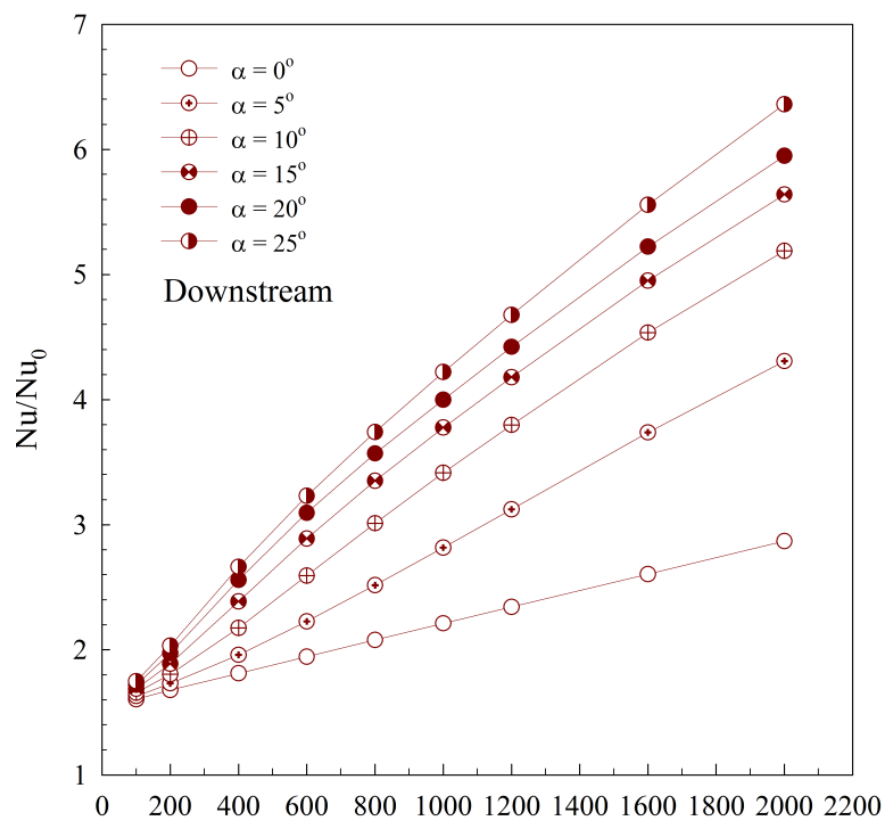

$\operatorname{Re}$

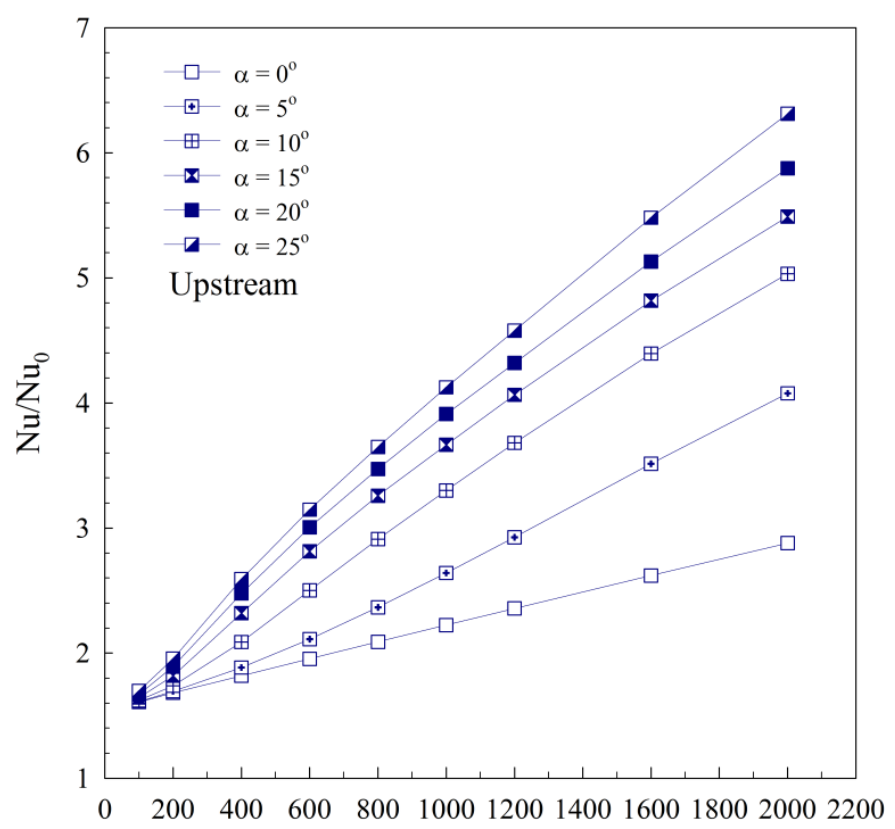

$\operatorname{Re}$

Fig. 15 The variations of the $N u / N u_{0}$ with the Reynolds number at various the flow attack angles for (a) downstream and (b) upstream.

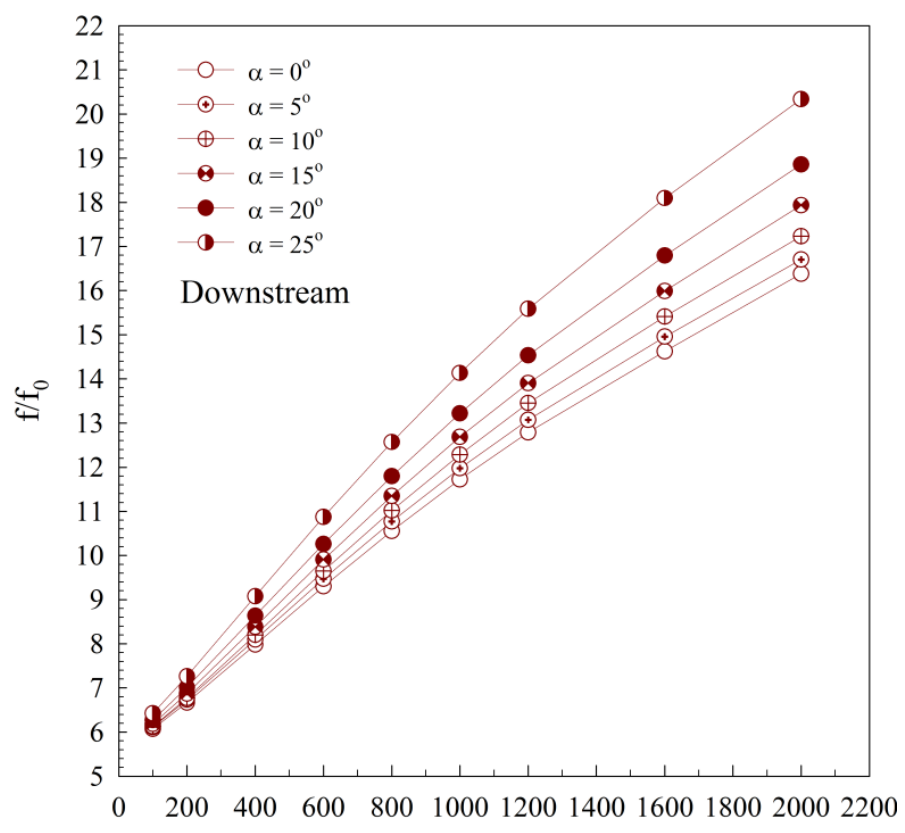

$\operatorname{Re}$

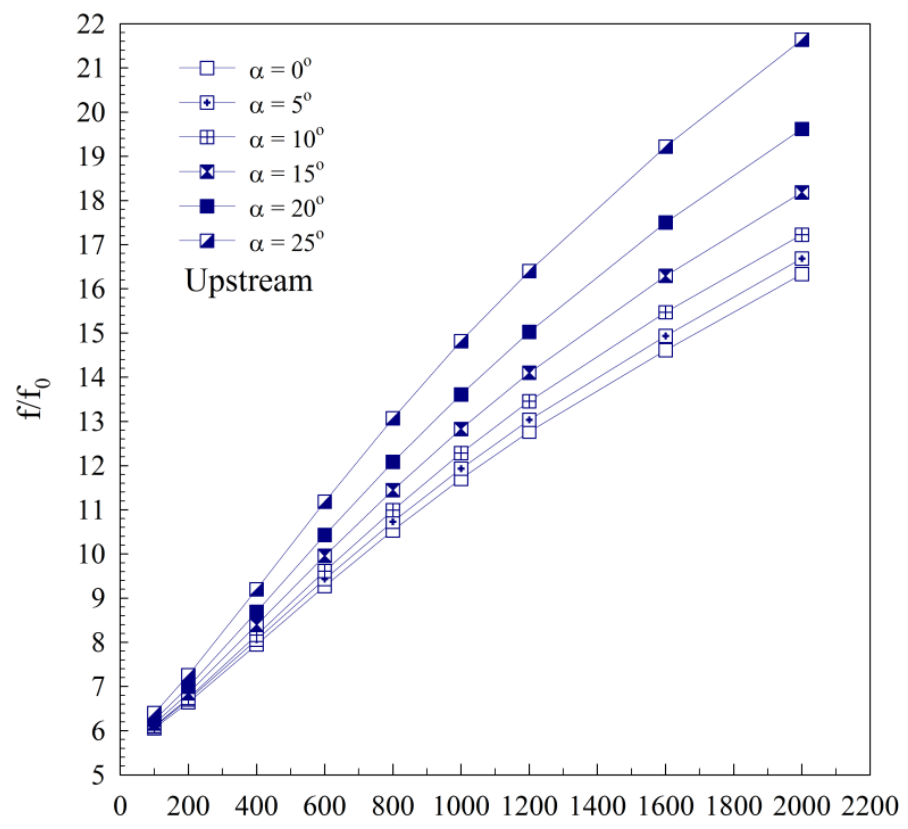

$\operatorname{Re}$

(b)

Fig. 16 The variations of the $f / f_{0}$ with the Reynolds number at various the flow attack angles for (a) downstream and (b) upstream. 


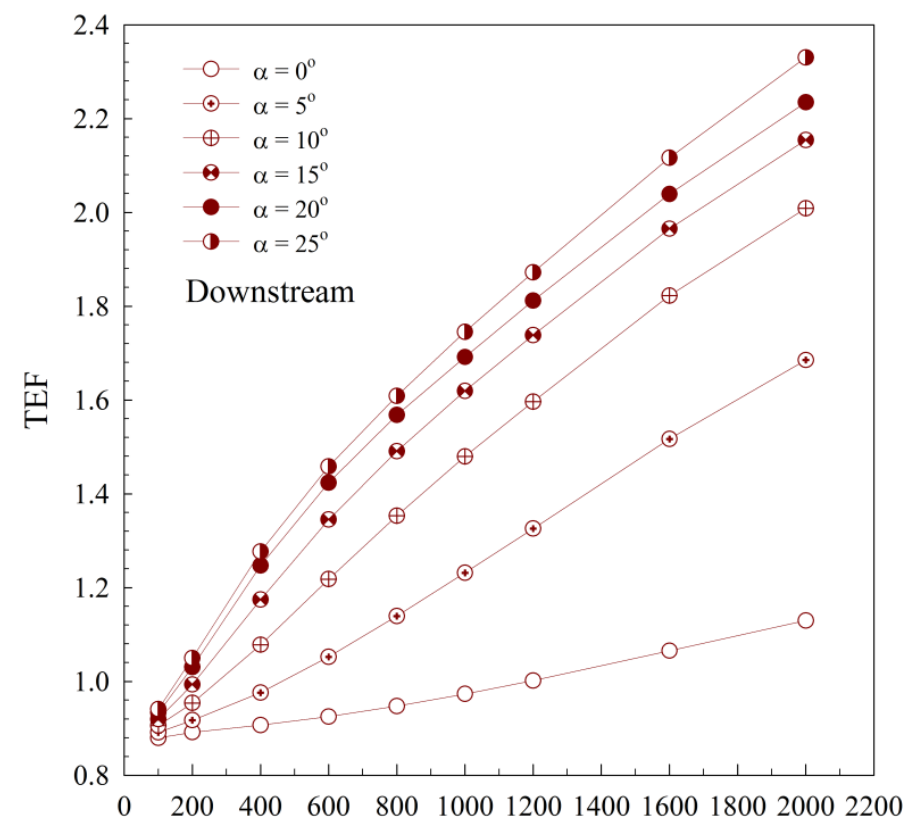

$\operatorname{Re}$

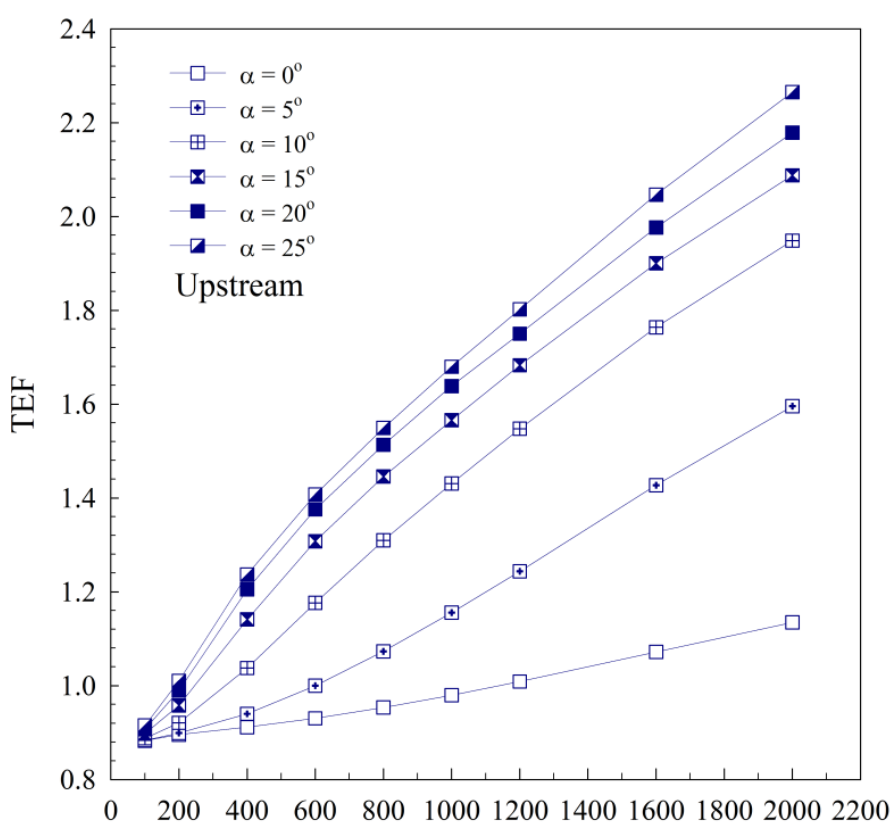

$\operatorname{Re}$

(a)

(b)

Fig. 17 The variations of the $T E F$ with the Reynolds number at various the flow attack angles for (a) downstream and (b) upstream.

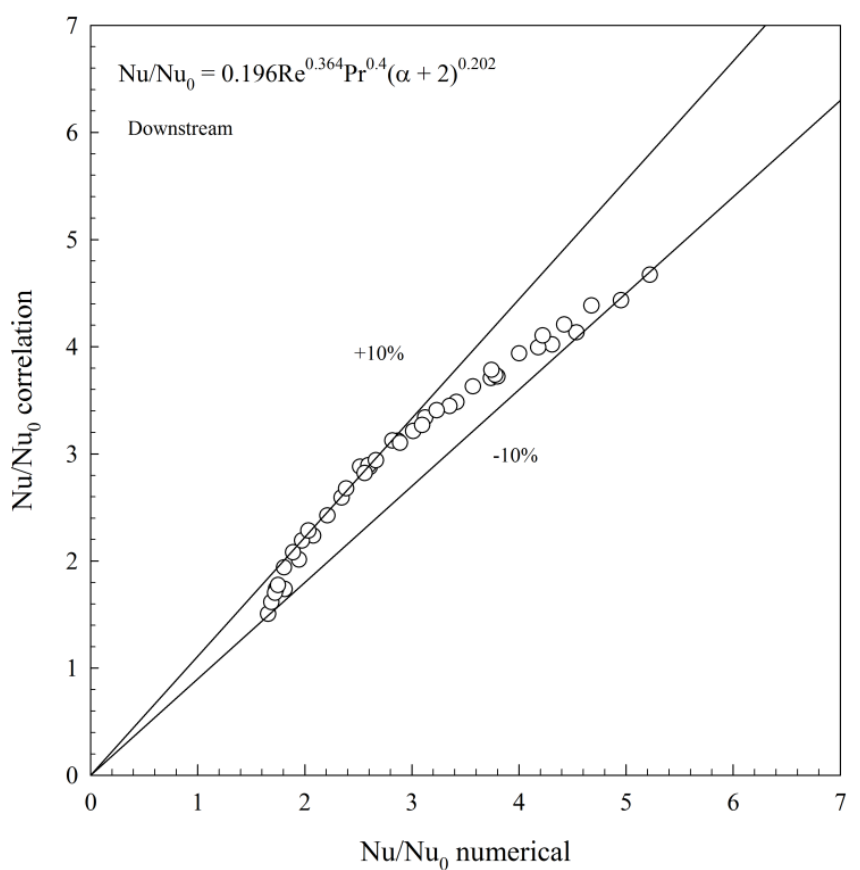

Fig. 18 The correlations of the $N u / N u_{0}$ for downstream of the $P D W V G$ in the tube heat exchanger.

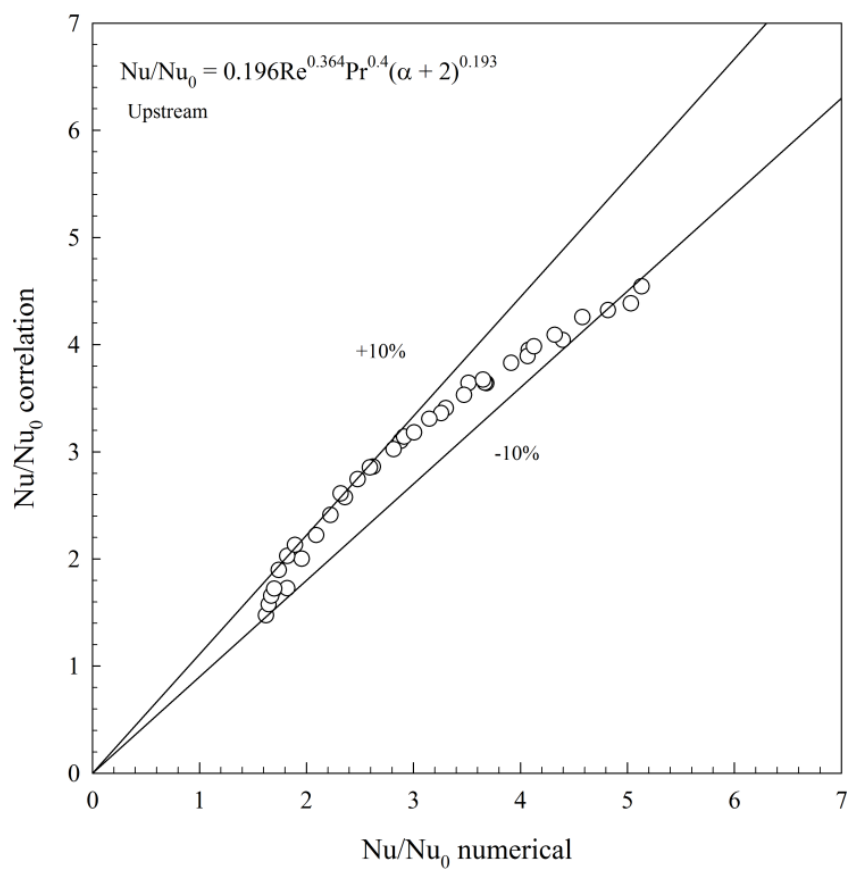

Fig. 19 The correlations of the $N u / N u_{0}$ for upstream of the $P D W V G$ in the tube heat exchanger. 


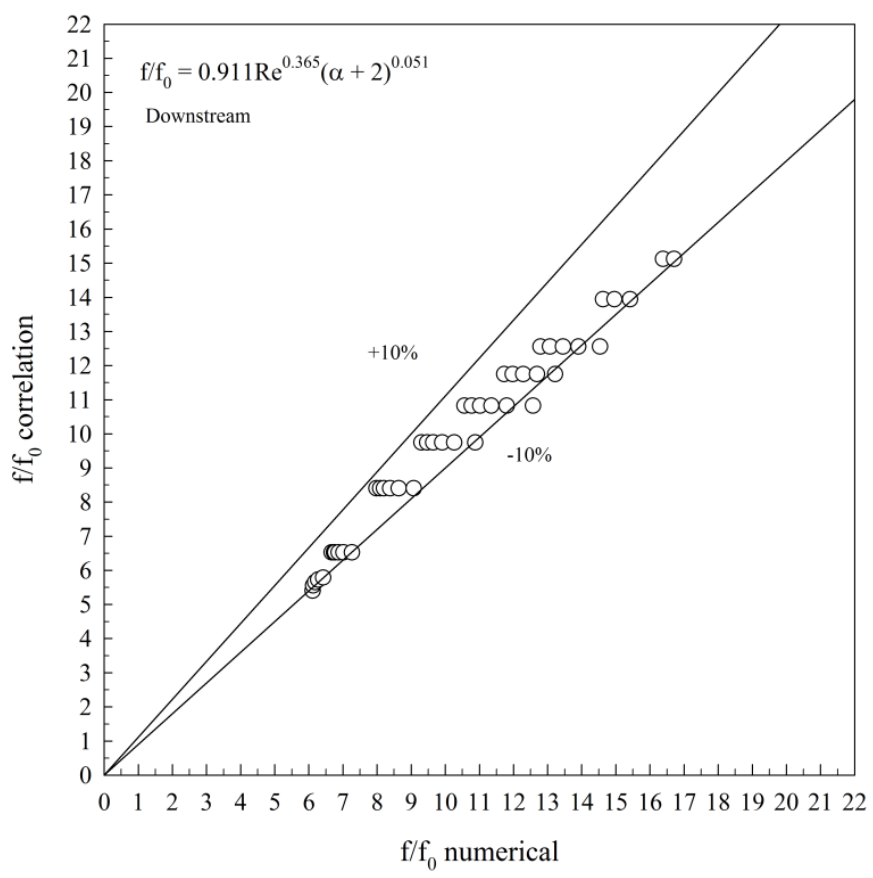

Fig. 20 The correlations of the $f / f_{0}$ for downstream of the $P D W V G$ in the tube heat exchanger.

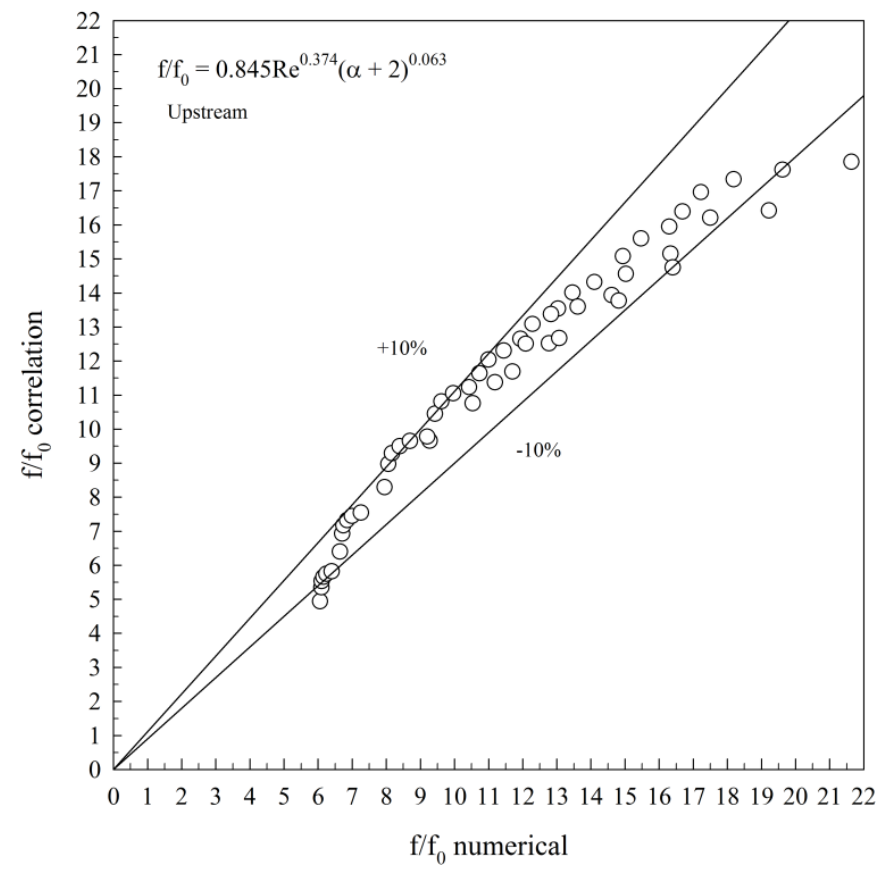

Fig. 21 The correlations of the $f / f_{0}$ for upstream of the $P D W V G$ in the tube heat exchanger.

The presence of the $P D W V G$ in the tube heat exchanger not only increases in heat transfer rate, but also increases the pressure. Figs. $16 a$ and $b$ present the variations of the $f l f_{0}$ with the Reynolds number at various the flow attack angles of the tube heat exchanger with $P D W V G$ for the winglet tip pointing downstream and upstream, respectively. Generally, the $f / f_{0}$ increase with increasing the Reynolds number and flow attack angle on both cases. The flow attack angle of $25^{\circ}$ performs the highest friction loss, while the flow attack angle of $0^{\circ}$ provides the reverse result. At $\alpha=0^{\circ}-10^{\circ}$, the $f l f_{0}$ for both cases is found to be nearly values for all Reynolds numbers. When $\alpha>10^{\circ}$, the $f / f_{0}$ of the winglet tip pointing upstream performs higher than the downstream case. The maximum $f l f_{0}$ of the $P D W V G$ with the tips pointing downstream and upstream is around 20.33 and 21.64 , respectively, at $R e=2000$ and $\alpha=25^{\circ}$. In addition, the use of $P D W V G$ in rang investigates gives the friction factor around 6-21.64 times higher than the smooth tube.

The thermal performance in terms of thermal enhancement factor, $T E F$, is reported in Figs. $17 a$ and $b$, respectively, for the winglet tip pointing downstream and upstream of the $P D W V G$ in the tube heat exchanger. Generally, the use of $P D W V G$ gives a higher thermal performance than the smooth circular tube. The TEF rises when increasing the Reynolds number and flow attack angle on both cases. The optimum TEF is around 2.33, 2.23, 2.15, 2.01,1.69 and 1.13 for the wingtip pointing downstream at the flow attack angles of $25^{\circ}, 20^{\circ}, 15^{\circ}$, $10^{\circ}, 5^{\circ}$ and $0^{\circ}$, respectively, and around $2.27,2.18,2.09,1.95,1.60$ and 1.13 , respectively, for the upstream case at $R e=2000$.

\section{CONCLUSIONS}

Numerical investigations on heat transfer, flow structure and thermal performance in a circular tube heat exchanger with the punched delta winglet vortex generators $(P D W V G)$ are presented for $R e=100-2000$. The influences of the flow attack angles, which tip converges to the center of the tube; $0^{\circ}, 5^{\circ}, 10^{\circ}, 15^{\circ}, 20^{\circ}, 25^{\circ}$, and flow directions; winglet tips pointing downstream and upstream, are studied. The major findings of the current investigations are as follows:

- $\quad$ The use of the $P D W V G$ in the circular tube heat exchanger leads to improve heat transfer rate and thermal performance when compared with the smooth tube with no $P D W V G$. The $P D W V G$ can generate the four main vortex flows through the test section.

- $\quad$ The clockwise and counter clockwise vortex flows are found when using $P D W V G$ with the tip pointing downstream and upstream, respectively. The vortex flows are clearly found when the flow attack angle of the $P D W V G$ higher than $0^{\circ}$ for both cases.

- The flow attack angle of $25^{\circ}$ performs the highest heat transfer rate, friction factor and thermal enhancement factor, while the flow attack angle of $0^{\circ}$ provided the lowest values.

- In range investigates, the heat transfer rate and friction loss are found to be around $1.6-6.31$ times and $6-21.64$ times higher than the smooth tube with no $P D W V G$, respectively. The optimum $T E F$ is around 2.33 at the flow attack angle of $25^{\circ}, R e=2000$ of the winglet tip pointing downstream.

- The correlations of the $N u / N u_{0}$ for the $P D W V G$ inserted in the tube heat exchanger with the winglet tips pointing downstream and upstream are presented in Figs. 18 and 19, respectively, for $\operatorname{Re}=100-2000$ and $\alpha=0^{\circ}-25^{\circ}$, while the variations of the $f l f_{0}$ are depicted in Figs. 20 and 21 for downstream and upstream, respectively. The correlation equations of the $N u / N u_{0}$ and $f / f_{0}$ of the current investigations are reported as Eqs. (10) - (13).

$$
\begin{aligned}
& \mathrm{Nu} / \mathrm{Nu}_{0}=0.196 \operatorname{Re}^{0.364} \operatorname{Pr}^{0.4}(\alpha+2)^{0.202}, \text { Downstream } \\
& \mathrm{Nu} / \mathrm{Nu}_{0}=0.196 \operatorname{Re}^{0.364} \operatorname{Pr}^{0.4}(\alpha+2)^{0.193}, \text { Upstream } \\
& \mathrm{f} / \mathrm{f}_{0}=0.911 \operatorname{Re}^{0.365}(\alpha+2)^{0.051}, \text { Downstream } \\
& \mathrm{f} / \mathrm{f}_{0}=0.845 \operatorname{Re}^{0.374}(\alpha+2)^{0.063}, \text { Upstream }
\end{aligned}
$$

\section{ACKNOWLEDGEMENTS}

This research was funded by King Mongkut's University of Technology North Bangkok Contract no. KMUTNB-GEN-59-62. The authors would like to thank Assoc. Prof. Dr. Pongjet Promvonge for suggestions. 


\section{NOMENCLATURE}

$\begin{array}{ll}D & \text { diameter of a circular tube }(\mathrm{m}) \\ f & \text { friction factor } \\ h & \text { convective heat transfer coefficient }\left(\mathrm{W} / \mathrm{m}^{2} \mathrm{~K}\right) \\ k & \text { thermal conductivity }(\mathrm{W} / \mathrm{m} \mathrm{K}) \\ N u & \text { Nusselt number } \\ p & \text { static pressure }(\mathrm{Pa}) \\ P r & \text { Prandtl number } \\ R e & \text { Reynolds number } \\ T & \text { temperature }(\mathrm{K}) \\ u_{i} & \text { velocity in } \mathrm{x}_{\mathrm{i}} \text {-direction }(\mathrm{m} / \mathrm{s}) \\ \bar{u} & \text { mean velocity in channel }(\mathrm{m} / \mathrm{s})\end{array}$

\section{Greek Letter}

$\begin{array}{ll}\mu & \text { dynamic viscosity }(\mathrm{Pa} \mathrm{s}) \\ \Gamma & \text { thermal diffusivity } \\ \alpha & \text { flow attack angle, (degree) } \\ T E F & \text { thermal enhancement factor }\left(\left(=\left(N u / N u_{0}\right)\left(f / f_{0}\right)^{-(1 / 3)}\right)\right. \\ \rho & \text { density }\left(\mathrm{kg} / \mathrm{m}^{3}\right)\end{array}$

$\begin{array}{ll}\text { Subscripts } & \\ \text { in } & \text { inlet } \\ 0 & \text { smooth tube } \\ \text { w } & \text { wall } \\ \text { pp } & \text { pumping power }\end{array}$

\section{REFERENCES}

Caliskan, S., 2014, "Experimental Investigation of Heat Transfer in a Channel with New Winglet-type Vortex Generators," International Journal of Heat and Mass Transfer, 78, 604-614. http://dx.doi.org/10.1016/j.ijheatmasstransfer.2014.07.043

Deshmukh, P.W., and Vedula, R.P., 2014, "Heat Transfer and Friction Factor Characteristics of Turbulent Flow Through a Circular Tube Fitted with Vortex Generator Inserts," International Journal of Heat and Mass Transfer, 79, 551-560.

http://dx.doi.org/10.1016/j.ijheatmasstransfer.2014.08.042

Du, X., Feng, L., Yang, Y., and Yang, L., 2013, "Experimental Study on Heat Transfer Enhancement of Wavy Finned Flat Tube with Longitudinal Vortex Generators," Applied Thermal Engineering, 50(1), $55-62$.

http://dx.doi.org/10.1016/j.applthermaleng.2012.05.024

Du, X., Feng, L., Li, L., Yang, L., and Yang, Y., 2014, "Heat Transfer Enhancement of Wavy Finned Flat Tube by Punched Longitudinal Vortex Generators," International Journal of Heat and Mass Transfer, 75, 368-380. http://dx.doi.org/10.1016/j.ijheatmasstransfer.2014.03.081

Ebrahimi, A., Roohi, E., and Kheradmand, S., 2015, "Numerical Study of Liquid Flow and Heat Transfer in Rectangular Microchannel with Longitudinal Vortex Generators," Applied Thermal Engineering, 78(5), 576-583. http://dx.doi.org/10.1016/j.applthermaleng.2014.12.006

Gholami, A.A., Wahid M.A., Mohammed, H.A., 2014, "Heat Transfer Enhancement and Pressure Drop for Fin-and-tube Compact Heat Exchangers with Wavy Rectangular Winglet-type Vortex Generators," International Communications in Heat and Mass Transfer, 54, 132-140. http://dx.doi.org/10.1016/j.icheatmasstransfer.2014.02.016
Gong, B., Wang, L.B., and Lin, Z.M., 2015, "Heat Transfer Characteristics of a Circular Tube Bank Fin Heat Exchanger with Fins Punched Curve Rectangular Vortex Generators in the Wake Regions of the Tubes," Applied Thermal Engineering, 75, 224-238. http://dx.doi.org/10.1016/j.applthermaleng.2014.09.043

He, Y.L., Han, H., Tao, W.Q., and Zhang, Y.W., 2012, "Numerical Study of Heat-transfer Enhancement by Punched Winglet-type Vortex Generator Arrays in Fin-and-tube Heat Exchangers," International Journal of Heat and Mass Transfer, 55(21-22), 5449-5458. http://dx.doi.org/10.1016/i.ijheatmasstransfer.2012.04.059

He, Y.L., Chu, P., Tao, W.Q., Zhang, Y.W., and Xie, T., 2013, "Analysis of Heat Transfer and Pressure Drop for Fin-and-tube Heat Exchangers with Rectangular Winglet-type Vortex Generators," Applied Thermal Engineering, 61(2), 770-783. http://dx.doi.org/10.1016/j.applthermaleng.2012.02.040

Incropera, F., and Dewitt, P.D., 2006, Introduction to Heat Transfer, $5^{\text {rd }}$ ed., John Wiley \& Sons, Hoboken, NJ.

Khoshvaght-Aliabadi, M., Sartipzadeh, O., and Alizadeh, A., 2015, “An Experimental Study on Vortex-generator Insert with Different Arrangements of Delta-winglets," Energy, 82, 629-639. http://dx.doi.org/10.1016/j.energy.2015.01.072

Li, L., Du, X., Zhang, Y., Yang, L., and Yang, Y., 2015, "Numerical Simulation on Flow and Heat Transfer of Fin-and-tube Heat exchanger with Longitudinal Vortex Generators," International Journal of Thermal Sciences, 92, 85-96.

http://dx.doi.org/10.1016/j.ijthermalsci.2015.01.030

Lotfi, B., Zeng, M., Sundén, B., and Wang, Q., 2014, “3D Numerical Investigation of Flow and Heat Transfer Characteristics in Smooth Wavy Fin-and-elliptical Tube Heat Exchangers using New Type Vortex Generators," Energy, 73, 233-257.

http://dx.doi.org/10.1016/j.energy.2014.06.016

Min, C., Qi, C., Wang, E., Tian, L., and Qin, Y., 2012, "Numerical Investigation of Turbulent Flow and Heat Transfer in a Channel with Novel Longitudinal Vortex Generators," International Journal of Heat and Mass Transfer, 55(23-24), 7268-7277.

http://dx.doi.org/10.1016/j.ijheatmasstransfer.2012.07.055

Patankar, S.V., 1980, Numerical Heat Transfer and Fluid Flow, McGraw-Hill, New York.

Wang, Y., He, Y.L., Yang, W.W., and Cheng, Z.D., 2015, "Numerical Analysis of Flow Resistance and Heat Transfer in a Channel with Delta Winglets under Laminar Pulsating Flow," International Journal of Heat and Mass Transfer, 82, 51-65.

http://dx.doi.org/10.1016/j.ijheatmasstransfer.2014.11.016

Wu, J.M., and Tao, W.Q., 2012, "Effect of Longitudinal Vortex Generator on Heat Transfer in Rectangular Channels," Applied Thermal Engineering, 37, 67-72.

http://dx.doi.org/10.1016/j.applthermaleng.2012.01.002

Wu, J.M., Zhang, H., Yan, C.H., and Wang, Y., 2012, "Experimental Study on the Performance of a Novel Fin-tube Air Heat Exchanger with Punched Longitudinal Vortex Generator," Energy Conversion and Management, 57, 42-48.

http://dx.doi.org/10.1016/j.enconman.2011.12.009 